\title{
Nuclear Factor I Coordinates Multiple Phases of Cerebellar Granule Cell Development via Regulation of Cell Adhesion Molecules
}

\author{
Wei Wang, ${ }^{1}$ Debra Mullikin-Kilpatrick, ${ }^{1}$ James E. Crandall, ${ }^{1,2}$ Richard M. Gronostajski, ${ }^{3}$ E. David Litwack,${ }^{4}$ and \\ Daniel L. Kilpatrick ${ }^{1}$ \\ ${ }^{1}$ Department of Cellular and Molecular Physiology and Program in Neuroscience, University of Massachusetts Medical School, Worcester, Massachusetts \\ $01655,{ }^{2}$ E. K. Shriver Center/University of Massachusetts Medical School, Waltham, Massachusetts 02452, ${ }^{3}$ Department of Biochemistry and Program in \\ Neuroscience, State University of New York at Buffalo, Buffalo, New York 14214-3000, and ${ }^{4}$ Department of Anatomy/Neurobiology and Program in \\ Neuroscience, University of Maryland, Baltimore, School of Medicine, Baltimore, Maryland 21201
}

A central question is how various stages of neuronal development are integrated as a differentiation program. Here we show that the nuclear factor I (NFI) family of transcriptional regulators is expressed and functions throughout the postmitotic development of cerebellar granule neurons (CGNs). Expression of an NFI dominant repressor in CGN cultures blocked axon outgrowth and dendrite formation and decreased CGN migration. Inhibition of NFI transactivation also disrupted extension and fasciculation of parallel fibers as well as CGN migration to the internal granule cell layer in cerebellar slices. In postnatal day $17 \mathrm{Nfia}$-deficient mice, parallel fibers were greatly diminished and disoriented, CGN dendrite formation was dramatically impaired, and migration from the external germinal layer (EGL) was retarded. Axonal marker expression also was disrupted within the EGL of embryonic day $18 \mathrm{Nfib}$-null mice. NFI regulation of axon extension was observed under conditions of homotypic cell contact, implicating cell surface proteins as downstream mediators of its actions in CGNs. Consistent with this, the cell adhesion molecules ephrin B1 and N-cadherin were identified as NFI gene targets in CGNs using inhibitor and $\mathrm{Nfi}$ mutant analysis as well as chromatin immunoprecipitation. Functional inhibition of ephrin B1 or $\mathrm{N}$-cadherin interfered with CGN axon extension and guidance, migration, and dendritogenesis in cell culture as well as in situ. These studies define NFI as a key regulator of postmitotic CGN development, in particular of axon formation, dendritogenesis, and migratory behavior. Furthermore, they reveal how a single transcription factor family can control and integrate multiple aspects of neuronal differentiation through the regulation of cell adhesion molecules.

Key words: transcription; neuron; differentiation; axon; migration; dendrite

\section{Introduction}

During nervous system development, immature neurons are born in spatially and temporally distinct patterns and undergo specialized differentiation programs that give rise to unique populations of mature neurons. This maturation involves a series of morphological stages in which neurons migrate and elaborate axons and dendrites, resulting in appropriate synaptic intercon-

Received Aug. 11, 2006; revised March 28, 2007; accepted April 23, 2007.

This work was supported by Public Health Service Grants CA79999 (D.L.K.) and R01 NS050515 (E.D.L.), and Diabetes Endocrinology Research Center Grant DK32520 to the University of Massachusetts Medical School. We thank George Gagnon for his excellent technical assistance with neuronal primary cultures and other facets of this work and Rachel Stock for help with immunohistochemistry. The pMSCV2.2 IRES-GFP plasmid and the 293GPG retroviral packaging cell line were generous gifts from Dr. Rachel Gerstein (University of Massachusetts Medical School, Worcester, MA). Antibodies were generously provided for Math1 (Jane Johnson, University of Texas Southwestern, Dallas, TX), NFI-C (Naoko Tanese, New York University, New York, NY), and SMI-312 (Stephen Lambert, University of Massachusetts Medical School, Worcester, MA). N-cadherin antagonist peptides were kindly provided by Dr. Mukur Gupta (Adherex, Durham, NC).

Correspondence should be addressed to Daniel L. Kilpatrick, Physiology Department, University of Massachusetts Medical School, BSB S4-139, 55 Lake Avenue North, Worcester, MA 01655. E-mail: daniel.kilpatrick@ umassmed.edu.

D01:10.1523/JNEUROSCI.0180-07.2007

Copyright $\odot 2007$ Society for Neuroscience $\quad$ 0270-6474/07/276115-13\$15.00/0 nections. The coordination of these various events as a developmental program is a fundamental question.

Cerebellar granule neurons (CGNs) provide an excellent model for studying various aspects of neuronal development. In the postnatal cerebellum, granule neuron progenitors proliferate in the external germinal layer (EGL) and then form immature neurons within the premigratory zone (PMZ). Within the PMZ, CGNs elaborate bipolar axons that form fascicles of parallel fibers and migrate tangentially. CGNs then extend a third, radial process and migrate through the molecular layer (ML) along Bergmann glia to form the internal granule cell layer (IGL). Postmigratory CGNs complete their differentiation in the IGL by forming dendrites and synaptic connections with mossy fibers and Golgi type II neurons.

A number of transcription factors regulate the lineage specification, spatial organization, and development of CGNs, including Math1 (mouse atonal homolog 1) (Ben-Arie et al., 1997; Jensen et al., 2004), En-2 (engrailed protein 2) (Millen et al., 1995), RU49/Zipro1 (zinc finger proliferation 1) (Yang et al., 1999), Pax-6 (paired box gene 6) (Yamasaki et al., 2001; Swanson et al., 2005), Notch-2 (Solecki et al., 2001), Barhl1 (BarH-like 1) 
(Li et al., 2004), and Zic1 and Zic2 (zinc finger protein of the cerebellum 1 and 2) (Aruga et al., 1998, 2002). These trans regulators have been implicated in specific stages of CGN development, including progenitor migration from the rhombic lip (Gazit et al., 2004), proliferation and onset of differentiation within the EGL (Aruga et al., 1998, 2002; Yang et al., 1999; Solecki et al., 2001), axon formation (Yamasaki et al., 2001), and radial migration (Li et al., 2004). How various transcriptional mechanisms and downstream genes are integrated to elaborate successive stages of CGN development remains poorly understood.

Nuclear factor I (NFI) consists of a family of four genes ( $N f i a$, $N f i b, N f i c$, and $N f i x$ ) that each gives rise to multiple isoforms via alternative splicing (Gronostajski, 2000). This factor regulates target genes as homodimers and/or heterodimers and has been directly implicated in developmental and cell-specific gene regulation (Chaudhry et al., 1997; Gronostajski, 2000), including nervous system function and development. Mice lacking either Nfia or Nfib exhibit marked neurological defects, including agenesis of the corpus callosum, disruption of midline glia, tremor, and hydrocephalus (das Neves et al., 1999; Shu et al., 2003; Steele Perkins et al., 2005). Nfib-null mice also are defective in development of the basilar pons and hippocampus (Steele Perkins et al., 2005). However, specific roles and direct target genes within neurons for this family of trans regulators have been elusive.

Recently, NFI was shown to be an important transcriptional regulator of a CGN-specific gene. The $\alpha 6$ subunit of the $\mathrm{GABA}_{\mathrm{A}}$ receptor (Gabra6) is highly enriched in CGNs (Zheng et al., 1993), and its gene transcription is directly regulated by NFI (Wang et al., 2004). Although NFI is present in numerous neuronal subtypes as well as glia (Chaudhry et al., 1997), all four NFI genes are expressed at elevated levels in CGNs relative to other cerebellar cell types as well as cortical neurons (Wang et al., 2004). These findings suggested that the NFI family has additional important functions in CGNs besides Gabra6 regulation. Here, we demonstrate that NFI is a key regulator of postmitotic CGN development, controlling axon formation, migration, and dendritogenesis. Furthermore, we show that NFI exerts these multifaceted actions via the regulation of cell adhesion molecules.

\section{Materials and Methods}

Recombinant proteins, blocking peptides, and antibody. Mouse ephrin$\mathrm{B} 1 / \mathrm{Fc}$ and rat EphB1/Fc chimeric proteins were obtained from $\mathrm{R} \& \mathrm{D}$ Systems (Minneapolis, MN). N-cadherin antagonist peptides (HAVDI and INPISGQ) have been described previously (Williams et al., 2000a,b). $\mathrm{N}$-Acetyl-CHGVC- $\mathrm{NH}_{2}$ was used as a negative control peptide. The GC-4 N-cadherin blocking antibody was purchased from Sigma (St. Louis, MO).

Plasmids and cell lines. Self-inactivating lentiviruses expressing NFI dominant repressor (NFI/EnR) or the Drosophila engrailed repressor domain (EnR), both containing a C-terminal hemagglutinin (HA) tag, have been described previously (Wang et al., 2004). HA-tagged NFI/EnR and EnR fragments were released from their lentiviral expression vectors and inserted into the multiple cloning site of pMSCV2.2 internal ribosomal entry site-green fluorescent protein (GFP) to generate NFI/EnRand EnR-expressing retroviruses. Human embryonic kidney 293T cells were obtained from the American Type Culture Collection (Rockville, MD).

Production of vesicular stomatitis virus glycoprotein-pseudotyped lentiviral and retroviral particles. Vesicular stomatitis virus glycoprotein (VSVG)-pseudotyped lentiviruses were generated by transient cotransfection of the vector construct $(15 \mu \mathrm{g})$, the packaging construct pCMV $\Delta 8.91(10 \mu \mathrm{g})$, and the pMD.G VSVG viral envelope expression vector (5 $\mu \mathrm{g})$ into 293T cells using the Calcium Phosphate ProFection Mammalian Transfection System (Promega, Madison, WI) (Wang et al., 2004). Recombinant VSVG-pseudotyped retroparticles were generated by tran- sient transfection of retroviral plasmids into the 293GPG packaging cell line (Galipeau et al., 1999) using FuGENE 6 Transfection Reagent (Roche Applied Science, Indianapolis, IN). All viral supernatants were harvested and concentrated by ultracentrifugation.

Animals. CD1 mice were used for the preparation of CGNs and for immunohistochemical studies. $\mathrm{Nfia}^{-/-}$mice and control $\mathrm{Nfi}^{+/+}$littermates were on a C57BL/6NTac background (Shu et al., 2003). Nfib ${ }^{-1-}$ mice and control littermates (Steele Perkins et al., 2005) were on a C57BL/6/129S background, and Nfic-null mice were backcrossed onto a C57BL/6 background. All protocols used for mouse studies were approved by the Institutional Animal Care and Use Committee at the University of Massachusetts Medical School and were in full compliance with the National Institutes of Health Guide and Use of Laboratory Animals.

Cell and tissue culture studies. Mouse CGNs were prepared from 6-dold pups according to previously described procedures (Wang et al., 2004). Briefly, dissected cerebella were digested with $1 \%$ trypsin and 1 $\mathrm{mg} / \mathrm{ml}$ DNase (Sigma) in calcium-magnesium-free PBS, pH 7.4, at room temperature for $3 \mathrm{~min}$. CGNs were prepared by mechanical trituration and enriched by Percoll (Sigma) gradient centrifugation. The granule cell fraction was further purified by preplating the cells on poly-D-lysinecoated Petri dishes at $35^{\circ} \mathrm{C}$ for $1 \mathrm{~h}$. For assays of neurites and dendrites in dissociated cultures, cells were plated at a density of $5 \times 10^{4}$ cells $/ \mathrm{cm}^{2}$ onto poly-D-lysine/laminin-treated chamber slides in Neurobasal medium containing B-27 serum-free supplement, $2 \mathrm{~mm}$ L-glutamine, 100 $\mathrm{U} / \mathrm{ml}$ penicillin, and $100 \mu \mathrm{g} / \mathrm{ml}$ streptomycin (pen-strep) (Invitrogen, Grand Island, NY) and 0.45\% D-glucose. Reaggregate cultures were prepared as described by Gao et al. (1991). Briefly, reaggregates were formed by incubating purified CGN progenitors for $\sim 20 \mathrm{~h}$ on uncoated tissue culture dishes in MEM (Sigma) containing 10\% fetal bovine serum, $0.45 \% \mathrm{D}$-glucose, pen-strep, and $2 \mathrm{~mm}$ L-glutamine at a cell density of $4 \times 10^{6} / \mathrm{ml}$. Reaggregates were then washed and cultured in Neurobasal/B27 medium on poly-D-lysine/laminin-treated chamber slides at $37^{\circ} \mathrm{C} / 5 \% \mathrm{CO}_{2}$.

Migration assays were performed using polycarbonate membrane filters (pore size, $5 \mu \mathrm{m}$ ) inserted into 24-well Boyden chamber-type Transwells (Costar, Cambridge, MA). The undersurfaces of the membrane inserts were coated with laminin at $20 \mu \mathrm{g} / \mathrm{ml}$ in PBS for $2 \mathrm{~h}$ at $37^{\circ} \mathrm{C}$. Granule cells $\left(10^{4}\right)$ were added in Neurobasal/B27 medium to the upper chamber and allowed to migrate into the coated undersurface at $37^{\circ} \mathrm{C}$ for $16 \mathrm{~h}$. Cells remaining on the upper membrane surface were wiped off, and the inserts were fixed with $4 \%$ paraformaldehyde and stained with bisbenzimide. For viral studies, cells were transduced with lentivirus during reaggregate formation in suspension cultures. The next day, cells were enzymatically dissociated and added to Transwell plates as above. Cerebellar slice cultures were performed as described previously (Wang et al., 2005) using either sagittal or coronal sections. Briefly, $250 \mu \mathrm{m}$ sections were cut from postnatal day 7 (P7) mouse cerebella, embedded in 5\% agarose, and incubated in MEM with 10\% FBS, 2 mM L-glutamine, pen-strep, and $0.45 \% \mathrm{D}$-glucose at $35^{\circ} \mathrm{C}$. Slices were then placed on Transwell membrane inserts (Costar) and cultured in Neurobasal/B27 medium at $37^{\circ} \mathrm{C} / 5 \% \mathrm{CO}_{2}$. GFP-positive $\left(\mathrm{GFP}^{+}\right)$cells were analyzed solely within the cerebellar vermis.

Cell cultures (both dissociated and reaggregate) were infected with lentivirus at a multiplicity of infection of $2-4$ as described previously (Wang et al., 2005), resulting in $>90 \%$ infection of CGNs. For slice experiments, the retroviral titer was reduced to $4 \times 10^{7}$ infectious units per well to permit visualization of individual $\mathrm{GFP}^{+}$cells.

Bromodeoxyuridine incorporation assays. CGN reaggregates were allowed to form in the presence of lentiviral expression vectors for $20 \mathrm{~h}$. They were then labeled with $10 \mu \mathrm{M}$ bromodeoxyuridine (BrdU) (Roche Applied Science) for an additional $24 \mathrm{~h}$. Cells were then redissociated into single cells, allowed to attach to chamber slides treated with poly-Dlysine and laminin, and then fixed with $4 \%$ paraformaldehyde. DNA denaturation was accomplished using $2 \mathrm{~N} \mathrm{HCl}$ for $30 \mathrm{~min}$ at $37^{\circ} \mathrm{C}$, followed by neutralization with two changes of $0.1 \mathrm{~m}$ sodium borate buffer, $\mathrm{pH} 8.5$, for $10 \mathrm{~min}$ each. BrdU-labeled cells were detected using antiBrdU antibody (1:5000, mAb 3518; Chemicon, Temecula, CA).

Isolation of RNA and reverse transcription-PCR. Total RNA was extracted from tissues and cells using Tri reagent (Sigma). First-strand 
cDNAs were synthesized with oligo- $\mathrm{dT}_{12-18}$ primers or random hexamers using the SuperScript reverse transcription (RT)-PCR system (Invitrogen). Transcripts were assayed by semiquantitative RT-PCR using the following primers: ephrin B1 (forward primer, TTGTGGCTATGGTCGTGC; reverse primer, GCTTGTCTCCAATCTTCG) and $\mathrm{N}$-cadherin (forward primer, TTGACTTTGAAACGAATAGG; reverse primer, TGATCTGCCCATTCACG). 18S ribosomal RNA was assayed for normalization purposes. Other primer sequences are available on request.

DiI labeling of parallel fibers and granule cells. P17 cerebella were fixed with $4 \%$ paraformaldehyde, embedded in 5\% agarose, and cut into 400 $\mu \mathrm{m}$ coronal sections throughout the vermis using a vibratome. Labeling with the lipophilic dye DiI was performed as described previously (Soha et al., 1997). Briefly, small DiI crystals were implanted into the ML at the midline, and sections were incubated in PBS at $37^{\circ} \mathrm{C}$ for $4 \mathrm{~d}$. Sections $(80$ $\mu \mathrm{m}$ ) were then prepared and analyzed for parallel fiber extension in the $\mathrm{ML}$ and the presence of CGN dendrites within the IGL using fluorescence microscopy.

Immunofluorescence. Cerebella from wild-type P6 mice and heads of P17 Nfia and Nfic knock-out mice and embryonic day 18 (E18) Nfib-null mice were fixed in $4 \%$ paraformaldehyde in phosphate buffer, $\mathrm{pH} 7.4$, imbedded with $30 \%$ sucrose, and cryosectioned at 15 or $50 \mu \mathrm{m}$ thickness as described previously (Wang et al., 2004). Primary CGNs or slice cultures were fixed with $4 \%$ paraformaldehyde for $30 \mathrm{~min}$ at room temperature. Immunofluorescence was performed as in previous studies (Wang et al., 2004). Samples were pretreated with $10 \%$ normal goat serum (Invitrogen), $0.05 \%$ Tween 20 , and $0.3 \%$ Triton X-100 in PBS at room temperature for $1 \mathrm{~h}$, followed by incubation with primary antibodies at $4^{\circ} \mathrm{C}$ overnight and then with secondary antibodies at room temperature for $1 \mathrm{~h}$. The following antibodies were used: anti-NFIA $(1: 10,000)$, antiNFIB (1:1000), and anti-NFIX (1:1000) (Active Motif, Carlsbad, CA); anti-NFI-C (1:500; Dr. N. Tanese, New York University, New York, NY); anti-HA (1:2000; Bethyl Laboratory, Montgomery, TX) and for colabeling studies (1:400; Cell Signaling Technology, Danvers, MA); anti-GFP monoclonal antibody, anti-neuronal-specific nuclear protein (NeuN), and anti-neurogenic differentiation (NeuroD) (each at 1:1000; Chemicon); anti- $\beta$ tubulin isotype III monoclonal antibody (1:1000; Sigma); anti-Math1 (1:500; Dr. J. Johnson, University of Texas Southwestern, Dallas, TX); anti-cyclin D2 (1:200; Santa Cruz Biotechnology, Santa Cruz, CA); pan-axonal neurofilament monoclonal antibody (SMI-312, 1:1000); anti-ephrin B1 polyclonal antibody (1:200; Santa Cruz Biotechnology), anti-mouse N-cadherin (1:50; Developmental Studies Hybridoma Bank, University of Iowa, Iowa City, IA); anti-S100 $\beta$ (1:2000; Sig$\mathrm{ma}$ ); and anti-calbindin-D28k monoclonal antibody (1:1000; Sigma). Secondary antibodies were conjugated to cyanine 3, AlexaFluor 594 (Invitrogen), or FITC. For studies of knock-out mice, sections were stained with $1 \mu \mathrm{g} / \mathrm{ml}$ bisbenzimide (Sigma) after treatment with secondary antibodies.

Chromatin immunoprecipitation assays. Chromatin immunoprecipitation (ChIP) assays were performed as described previously (Wang et al., 2004). Briefly, $6 \mathrm{~d}$ in vitro (DIV) CGN cultures or nuclei isolated from P15 mouse cerebella were crosslinked with $1 \%$ formaldehyde for 5 min at $37^{\circ} \mathrm{C}$. Immunostaining confirmed that $>85 \%$ of nuclei from P15 cerebella were positive for NeuN, a granule neuron marker in the mouse cerebellum (Weyer and Schilling, 2003). Cells or nuclei were then collected and lysed in SDS buffer (1\% SDS, 10 mm EDTA, 50 mм Tris-HCl, $\mathrm{pH} 8.1,1 \mathrm{~mm}$ phenylmethylsulfonyl fluoride, and $1 \times$ protease inhibitor mixture mix). Chromatin was sonicated to an average length of $600 \mathrm{bp}$, and NFI antibody was added to the lysate. After overnight incubation at $4^{\circ} \mathrm{C}$, immune complexes were collected with protein A-Sepharose (GE Healthcare, Little Chalfont, UK). The precipitated chromatin was treated with proteinase K and DNase-free RNase A, followed by overnight incubation to reverse the crosslinking. DNA was extracted and used as template for PCR assay of the mouse ephrin $\mathrm{B} 1$ and $\mathrm{N}$-cadherin promoters. PCR primer sequences were as follows: ephrin B1 (forward, $5^{\prime}$-TGGTAGCTCCCATTTAGTGTC-3'; reverse, 5' -TCGCAGGTCTCAGAAGGTC-3'); N-cadherin (forward, 5'-TGCTGCCTGGTTGTTTCTC-3'; reverse, 5' - GCTAATAAAGCCATTCTAGTAGTGA-3').

Image analysis and statistical tests. Images of immunostaining or cell cultures were obtained by computer-assisted microscopy using Nikon (Tokyo, Japan) Optiphot or Zeiss (Oberkochen, Germany) Axiovert135 inverted microscopes. Images were obtained and analyzed using Axio Vision 4.4 (Zeiss) software. For reaggregate studies, only cellular clusters having similar sizes were compared. For granule cell migration, CGN cell bodies were identified by staining either for HA (for lentiviral experiments) or using bisbenzimide, and their distances from the reaggregate perimeter were determined as described previously (Hirotsune et al., 1998). Neurites were identified by $\beta$-III tubulin staining. To analyze neurite length, reaggregates were visually divided into quadrants, and the median neurite length for each quadrant was determined by measuring the longest and shortest neurites from the edge of the cell body cluster. The four quadrant values were then averaged to obtain the overall median neurite length for each reaggregate. Neurite density was determined by measuring the number of neurites extending beyond the edge of the cluster divided by the diameter of each reaggregate. In antibody-treated reaggregate cultures, outgrowth of their nonradial neurites was quantified by measuring the area occupied by all neurites and then normalizing to the area of each cell cluster. A minimum of 20 reaggregates were examined for each experimental treatment. Measurements of axon and dendrite length in dissociated CGN cultures were performed on captured images as described previously (Ronn et al., 2000) from 200-300 neurons per experiment. Dendrite density was defined as the average number of dendrites per cell.

For studies using cerebellar slice cultures, retroviral-transduced cells within the cerebellar cortex were identified by GFP immunostaining, and bisbenzimide was used to demarcate the EGL, ML, and IGL regions. Although progenitors for basket, stellate, Golgi, and glial cells can be transduced by retrovirus within the white matter region of the postnatal cerebellum (Zhang and Goldman, 1996), consistent with previous reports (Tomoda et al., 1999), $>90 \%$ of $\mathrm{GFP}^{+}$cells detected within these three cortical layers of cultured slices exhibited typical CGN morphologies (e.g., T-shaped axons in the EGL/ML and "claw"-like dendrites within the IGL). For migration, the number of labeled neurons in each cell layer was counted and expressed as a percentage of total $\mathrm{GFP}^{+}$cells. The lengths of newly forming parallel fibers in virus-expressing cells were measured within the PMZ/ML region using Axio Vision 4.4 software. The focal plane was adjusted as necessary to trace the axon process. To quantify altered axon orientation, a line was drawn along the local interface between the EGL and ML regions. The angle of divergence from the parallel determined by this line was measured for each growing $\mathrm{GFP}^{+}$ axon emerging from its cell body. Dendrite formation was quantified by counting the number of primary dendrites extending from $\mathrm{GFP}^{+} \mathrm{CGNs}$ within the deep IGL. At least 50-100 neurons were analyzed for each experimental treatment.

In all studies, a minimum of three independent experiments were performed, and data were statistically analyzed using the two-tail $t$ test. Results were expressed as the average $\pm \mathrm{SE}$, and $p$ values $<0.05$ were considered significant.

Western blot analysis. Total cellular protein was prepared from cerebellar tissue using radioimmunoprecipitation assay buffer. Western blotting was performed as described previously (Wang et al., 2004) using the same primary antibodies for ephrin B1 (1:500) and N-cadherin (1:100) as used for histological studies. The antibody for actin (1:3000) was from BD Bioscience (San Jose, CA).

\section{Results \\ NFI is expressed in CGNs throughout their postmitotic differentiation}

Previous studies demonstrated that NFI proteins are highly enriched in mature CGNs within the adult mouse cerebellum (Wang et al., 2004). To address their potential function during CGN development, we examined NFI protein expression in the early postnatal cerebellum. Immunohistochemical analysis revealed that NFIA, NFIB, and NFIX are readily detected within the IGL of P6 mice (Fig. 1). NFIC immunostaining was too weak to be reliably discerned (data not shown). NFIA, NFIB, and NFIX were localized to the nuclei of granule cells, consistent with a 
transcriptional role for these proteins. Furthermore, nuclear staining for these three family members was detected in fusiform cells within the ML, indicative of migrating postmitotic CGNs that have departed the EGL en route to the IGL (Fig. 1). Within the EGL, intense nuclear localization was observed in its deeper aspect, the PMZ, in which immature postmitotic granule neurons first appear. Staining within the outer proliferative region of the EGL was generally faint and nonspecific (Fig. 1), similar to a negative control (data not shown). Thus, NFI proteins are upregulated in CGNs as they become postmitotic and subsequently undergo radial migration and final maturation within the IGL.

\section{NFI transactivation is required for neurite outgrowth by CGNs}

The expression pattern for NFI proteins suggested that they might function during several stages of postmitotic CGN development, including axon formation and migration. Reaggregate cultures of CGNs were used to examine this question because they permit assessment of both of these processes. Purified CGN progenitors were allowed to form reaggregates in suspension cultures for $\sim 20 \mathrm{~h}$, followed by plating on a laminin-coated surface. After attachment, reaggregates initially extend axon-like neurites, followed by subsequent migration of cell nuclei along these extended processes (Gao et al., 1991; Bix and Clark, 1998). To probe NFI function, CGN progenitors were infected during reaggregation with lentiviral vectors that expressed either a dominant repressor form of NFI (NFI/EnR) or the Drosophila engrailed repressor domain alone (EnR) (Wang et al., 2004). As reported previously (Wang et al., 2005), lentiviral vectors quantitatively transduce cultured CGNs with high efficiency with a rapid onset of protein expression (within $6 \mathrm{~h}$ ) without affecting cell survival or differentiation.

The NFI dominant repressor dramatically impaired neurite extension from CGN reaggregates relative to EnR-transduced controls (Fig. $2 \mathrm{~A}$ ). Both reaggregate neurite density and neurite length were reduced threefold by NFI/EnR ( $p<0.001$ for each), with neurites often highly fasciculated and extending in an aberrant nonradial manner (Fig. 2A). Immunostaining for phosphorylated neurofilament confirmed that neurites extending from reaggregate cultures were axons (data not shown). Furthermore, CGN migration was greatly inhibited in NFI/EnRexpressing reaggregates (Fig. $2 \mathrm{~B}$ ). Very few migrating cells were observed, and these were present at relatively short distances. In contrast, EnR-expressing CGNs migrated considerable distances from reaggregates (Fig. $2 B$ ), identical to mock-infected cultures (data not shown).

CGN progenitors continue to proliferate in reaggregate suspensions (Gao et al., 1991). Because lentiviral expression occurred during re-aggregate formation in the above experiments, it was possible that the NFI dominant repressor affected CGN progenitor cell division and thereby indirectly altered their subsequent differentiation. However, addition of BrdU to reaggregates revealed that the NFI dominant repressor did not significantly affect the number of CGN progenitors undergoing $S$ phase, and there also was no effect of NFI/EnR on the percentage of surviving cells (data not shown). Thus, repression of NFI transactivation in CGNs reflects specific interference with the differentiation process per se. This is consistent with the postmitotic up-regulation of NFI protein observed in these cells (Fig. 1). Furthermore, NFI/EnR did not suppress expression of NeuroD or NeuN (data not shown), both of which are differentiation markers for granule neurons within the cerebellum (Miyata et al., 1999; Weyer and Schilling, 2003). Thus, onset of CGN differentiation was not generally affected.

CGNs elaborate neurites in dissociated cell cultures as part of a cell-intrinsic program (Powell et al., 1997). Interestingly, axons showed no significant differences in length or general morphology when dissociated CGNs were transduced with NFI/EnR or EnR proteins (Fig. $2 C$ and data not shown). One difference between reaggregate and dissociated cell experiments was that, in the former case, CGN progenitors were transduced with lentivirus for $20 \mathrm{~h}$ before plating on laminin, whereas dissociated cultures were infected during the plating step. It was therefore possible that the differential effects of NFI disruption between the two cultures reflected a more rapid and efficient repression of NFI function within reaggregates. To address this, reaggregates were transduced with NFI/EnR- or EnR-expressing lentiviruses in suspension cultures for $20 \mathrm{~h}$, and then they were disaggregated into individual cells before plating on laminin. No major differences in either the number of axon-bearing cells or axon length were observed under these circumstances (data not shown). Thus, NFI regulation of axon outgrowth by CGNs was only detected under conditions of homotypic cell contact present in reaggregate cultures.

\section{NFI controls dendrite formation in maturing CGNs}

In addition to its importance for earlier stages of CGN differentiation within the PMZ/ML, NFI also is required for the expression of the Gabra6 gene within the IGL (Wang et al., 2004). We therefore investigated whether NFI regulated dendritogenesis, which is also a late differentiation event occurring in the IGL. Dendrite formation in NFI/EnR-treated reaggregate cultures could not be discerned on individual CGN cell bodies within reaggregates. Dissociated CGNs were therefore transduced on 1 DIV with either NFI/EnR or EnR lentiviruses, and dendrite formation was examined on 4 DIV using mitogen-activated protein 2 (MAP2) as a marker. Suppression of NFI transactivation caused a marked reduction in dendritogenesis by CGNs (Fig. 2D). The NFI dominant repressor greatly reduced both dendrite length (4.0-fold; $p<0.001)$ as well as the number of dendritic processes per cell (2.4-fold; $p<0.001)$. Thus, in contrast to its effects on axon formation, NFI regulation of dendritogenesis occurred in dissociated cultures. 
A
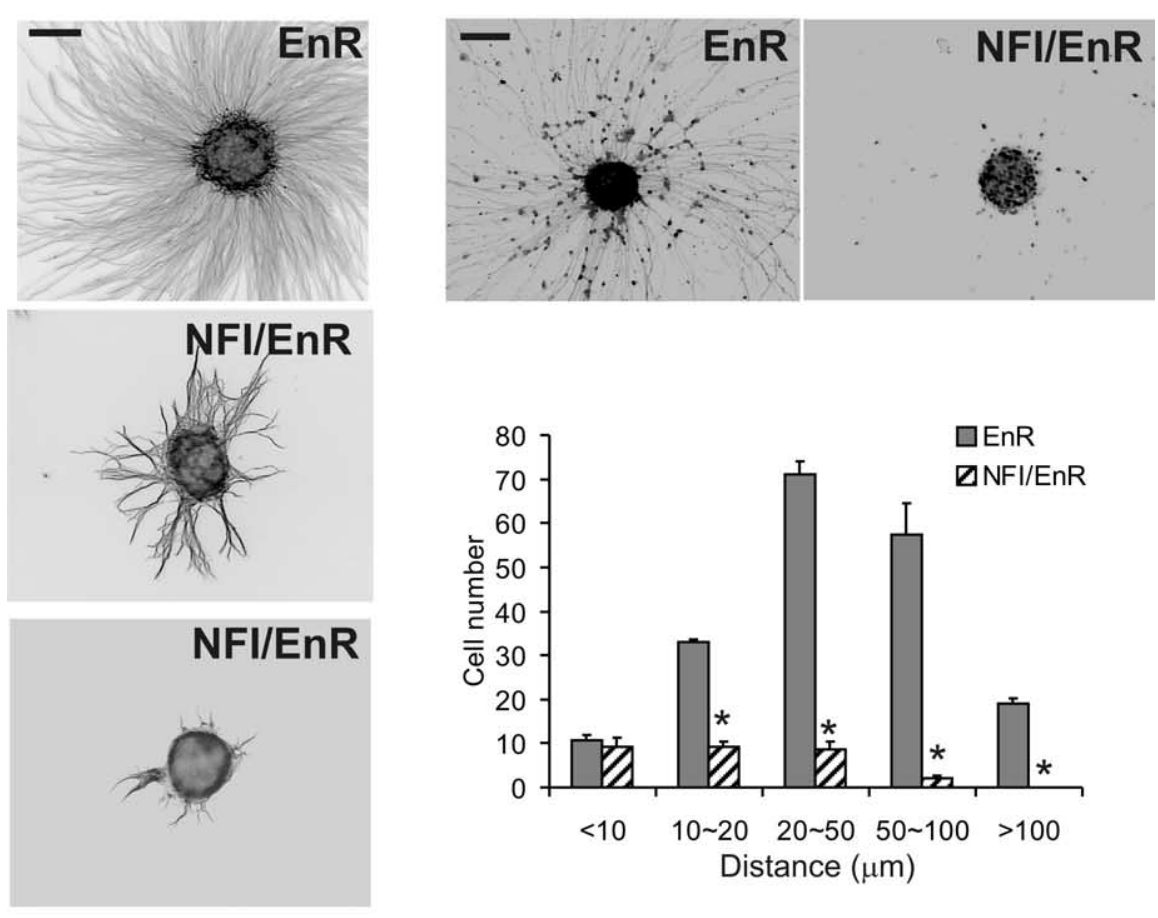

C
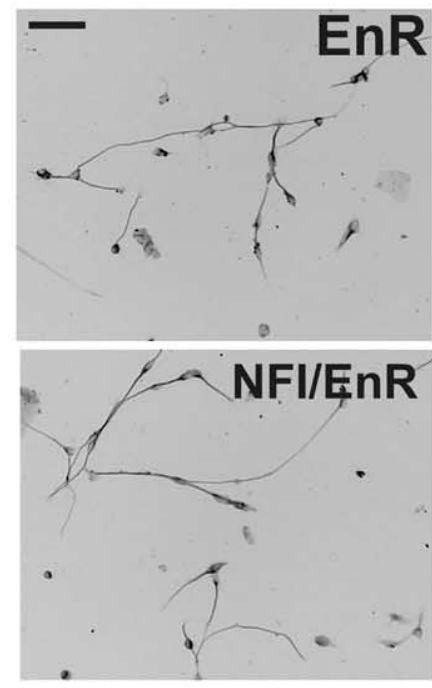

B

D
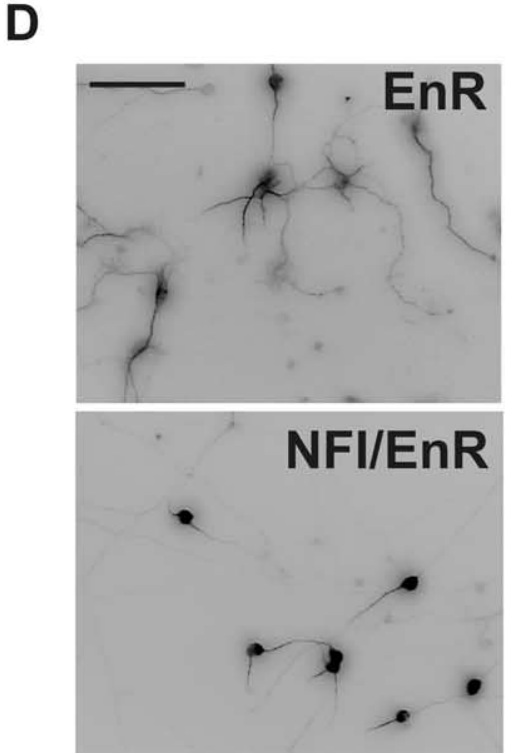

Figure 2. NFI regulates process formation and migration. $\boldsymbol{A}$, The NFI dominant repressor impairs neurite outgrowth from CGN reaggregates. CGNs were infected with lentivirus expressing $\mathrm{HA}$-tagged $\mathrm{NFI} / \mathrm{EnR}$ or EnR during cell reaggregation and examined $20 \mathrm{~h}$ after plating for neurite extension using $\beta$-III tubulin immunostaining. $\boldsymbol{B}, \mathrm{NFI}$ is required for migration of CGNs from reaggregates. Top, Reaggregates were stained for $\mathrm{HA}$ to identify transduced CGN nuclei. Bottom, The distribution of HA ${ }^{+}$neurons migrating from reaggregates. C, The NFI dominant repressor does not significantly affect neurite outgrowth in fully dissociated CGN cultures. Dissociated CGNs were infected with NFI/EnR or EnR virus on 0 DIV and stained for $\beta$-III tubulin on 2 DIV. D, NFI is required for dendrite formation in dissociated CGN cultures. CGNs were transduced with NFI/EnR or EnR lentiviruses and then stained for MAP2. Both dendrite length and number per cell were significantly reduced by the NFI dominant repressor relative to control. ${ }^{*} p<0.001$, significantly different from control. Scale bars: $\boldsymbol{A}-\boldsymbol{C}, 100 \mu \mathrm{m} ; \boldsymbol{D}, 50 \mu \mathrm{m}$. were used to assess cell body migration and parallel fiber formation within transduced neurons. Although a high percentage of EnR-transduced CGNs emigrated from the EGL to the ML and IGL, most NFI/EnR-expressing CGNs remained within the EGL region, and only a small fraction reached the IGL (Fig. $3 A$ ). Thus, departure of CGNs from the EGL was markedly inhibited by disruption of NFI transactivation.

In coronal sections infected with the control EnR virus, GFP-expressing CGNs extended parallel processes within the EGL/ML region (Fig. 3B). Axons of CGNs expressing the NFI dominant repressor were reduced in length 3.2 -fold $(p<$ 0.001). Furthermore, these processes were defasciculated, with an $\sim 10$-fold increase in fibers oriented toward the EGL and/or IGL (Fig. 3B). Thus, consistent with cell culture studies, NFI regulates the extension and orientation of parallel fibers as well as events required for CGN migration to the IGL in situ. Because very few CGNs reached the deep IGL in cerebellar slice cultures, it was not possible to reliably examine the effects of NFI inhibition on dendrite formation in this preparation.

\section{NFI regulates CGN migration}

The NFI dominant repressor markedly inhibited migration of CGNs in both reaggregate and slice cultures (Figs. $2 B, 3 A$ ). However, these experiments did not address whether NFI has a direct role in this process. For example, migration from reaggregates occurs along extended axons, and NFI/EnR severely inhibited axon formation in these cultures. Similarly, emigration of CGNs from the EGL to the IGL within cerebellar slices likely depends on progression of earlier events within the EGL/PMZ, including parallel fiber extension, which is disrupted in slice cultures by the NFI dominant repressor. To address the role of NFI in CGN migration per se, we performed modified Boyden assays in which dissociated CGNs were cultured on membranes coated on the opposing side with laminin. Expression of NFI/EnR inhibited CGN migration by $50 \%$ relative to EnR-transduced control cells $(p<0.01)$. Thus, NFI function also is necessary for CGN migratory behavior in addition to axon and dendrite formation.

\section{Disruption of NFI function alters differentiation of CGNs in situ}

We extended the above studies by examining the role of NFI in regulating CGN development within their native cellular environment using retroviral infection of cerebellar slices. Bicistronic vectors expressing NFI/EnR or EnR proteins together with GFP

\section{CGN development is altered at multiple steps in Nfia} knock-out mice

Based on the above findings, we examined whether CGN differentiation was altered in the cerebella of mice lacking NFI family members. Knock-out mice have been previously generated for Nfia, Nfib, and Nfic (das Neves et al., 1999; Grunder et al., 2002; 
A
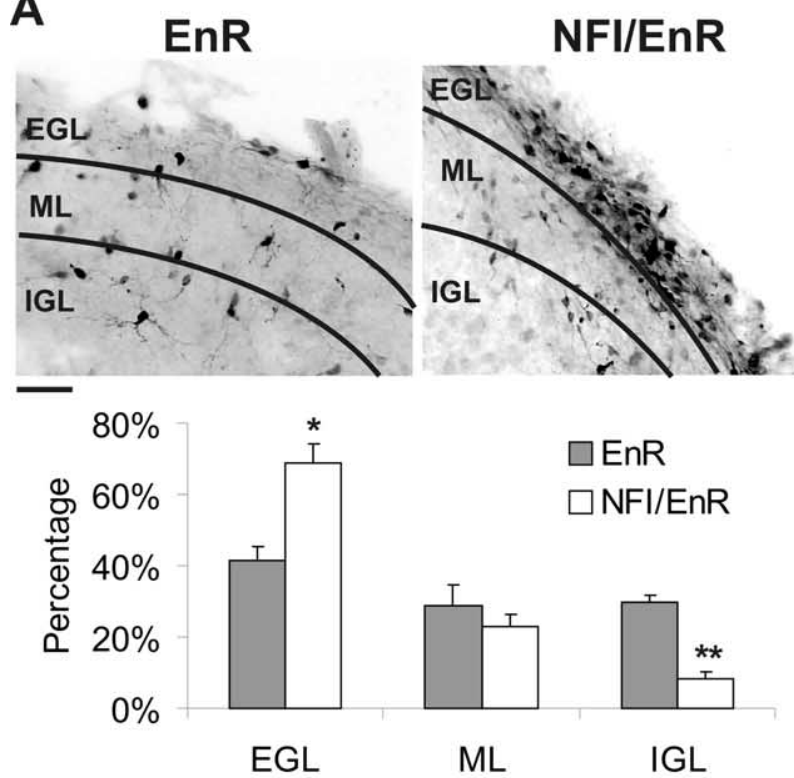

B EnR
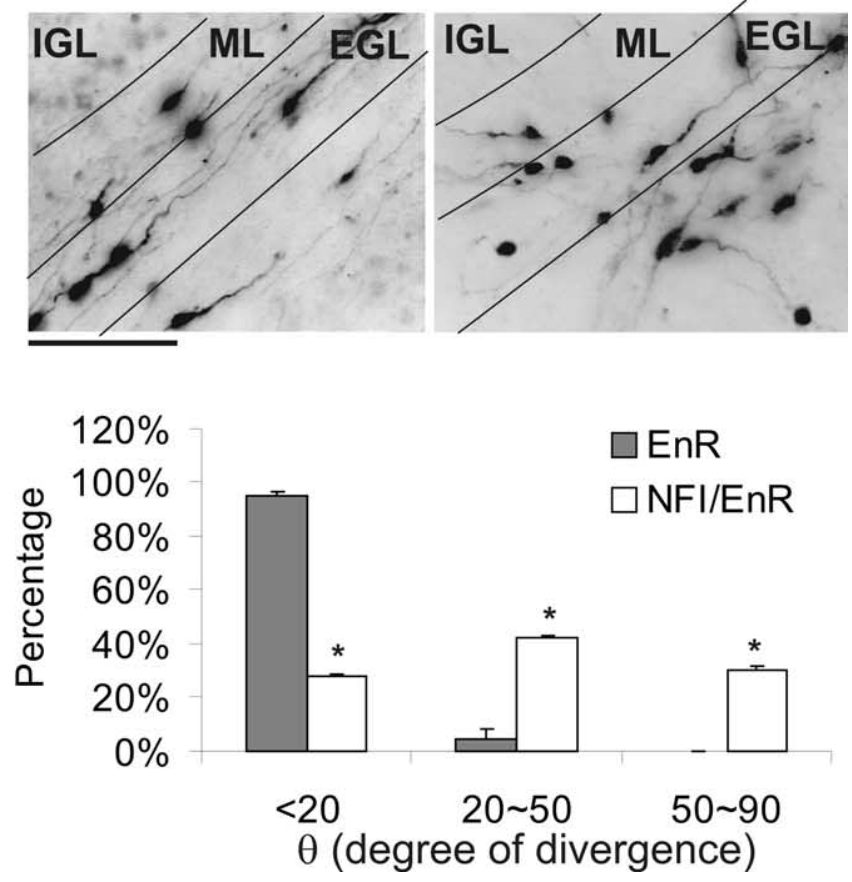

Figure 3. NFI transactivation is required for parallel fiber extension and CGN migration in situ. $\boldsymbol{A}$, The dominant repressor impairs CGN migration from the EGL to the IGL. Top, Representative images of GFP ${ }^{+}$CGNs infected with NFI/EnR or EnR retroviruses in sagittal cerebellar slices. Bottom, The percentage of GFP ${ }^{+}$cells present within the EGL, ML, and IGL expressed as the mean. ${ }^{*} p<0.05,{ }^{* *} p<0.001$, significantly different from EnR control. $\boldsymbol{B}$, Parallel fiber extension and orientation are markedly altered by inhibition of NFI. Top, GFP ${ }^{+}$immunostaining of parallel fibers within the EGL/ML region of coronal cerebellar slices transduced with $\mathrm{NFI} / \mathrm{EnR}$ or EnR retroviruses. Essentially all GFP ${ }^{+}$cells detected within this region contained bipolar processes typical of forming parallel fibers. Note that labeled cells lying below the indicated EGL region derive from an apposing EGL. Bottom, The angle of divergence $(\theta)$ from the parallel orientation, expressed in degrees, for GFP ${ }^{+}$axons. ${ }^{*} p<0.001$, significantly different from control. Scale bars, $50 \mu \mathrm{m}$.

Steele Perkins et al., 2003, 2005). Nfib-null mice die at birth as a result of lung defects (Grunder et al., 2002; Steele Perkins et al., 2005), whereas Nfia-null mice can survive to approximately P20 (das Neves et al., 1999; Wang et al., 2004). Examination of cere- bella from P17 Nfic-null mice showed no obvious phenotypes (data not shown), likely reflecting lower expression of this family member in the CNS (Chaudhry et al., 1997). Because postmitotic differentiation of CGNs is primarily postnatal, we initially examined Nfia mice to examine possible alterations in CGN maturation. In particular, we focused on P17 mice in which CGNs elaborate dendrites and have completed parallel fiber extension and radial migration. Analyses were limited to the cerebellar vermis throughout. Grossly, P17 $\mathrm{Nfia}^{-1-}$ mice exhibited a deformed foliation pattern relative to wild-type animals (Fig. 4A). Fissures were generally reduced in depth, and, in many instances, lobules appeared either stunted or poorly defined. For example, anterior lobules (I-V) were markedly underdeveloped, and segregation of lobules VI and VII appeared abnormal (Fig. 4A). Altered foliation has been associated previously with defects in postmitotic CGN development, including altered migration (Schwartz et al., 1997; Li et al., 2004).

DiI labeling (Soha et al., 1997) was used to assess both parallel fiber development and CGN dendrites in Nfia-null cerebellum. Within the ML of wild-type P17 cerebella, CGN axons exhibited a typical bipolar and parallel phenotype and extended over a considerable distance (Fig. 4B). However, ML axons were extremely short throughout both anterior and posterior aspects of the vermis in Nfia-null mice (Fig. $4 B$ ). Those processes that were sufficiently extended were typically misoriented, frequently extending at nearly a $90^{\circ}$ angle toward the meninges or the IGL (Fig. $4 B)$. Furthermore, dendrite formation was dramatically impaired on CGNs throughout the IGL of more anterior lobules in P17 $\mathrm{Nfia}^{-1-}$ vermes relative to wild-type (Fig. $4 \mathrm{C}$ ). Dendrites were generally not evident on these mutant CGNs and those few detected were extremely short, whereas CGNs in wild-type mice possessed typical claw-like dendrites.

Migration of CGNs from the EGL to the IGL is normally completed in mice by $\mathrm{P} 17$, and no migrating cells were identified in the ML of wild-type mice using NeuN and NeuroD as CGN markers (Fig. $4 D$ and data not shown). However, although many CGNs completed migration to the IGL in P17 Nfia-null mice, numerous CGN nuclei were observed in the ML (Fig. $4 \mathrm{D}$ and data not shown). These exhibited fusiform shapes typical of migrating CGNs, indicating retarded migration in Nfia knock-out mice. Furthermore, a residual layer of NeuroD ${ }^{+}$and $\mathrm{NeuN}^{+}$ cells (on average, two to three cells thick) was still present in the EGL/PMZ of mutants at this age, which was absent in $+/+$ mice (Fig. $4 D$ and data not shown). No Math $1^{+}$or cyclin $\mathrm{D} 2{ }^{+}$cells were detected within the residual EGL (data not shown), indicating the absence of CGN progenitors in this region. Thus, loss of Nfia disrupts parallel fiber extension and orientation, dendritogenesis, and departure of postmitotic CGNs from the EGL/PMZ.

The number and organization of calbindin ${ }^{+}$Purkinje neurons were similar in P17 wild-type and Nfia knock-out mice (Fig. $4 E$ ), indicating that alterations in CGNs were not attributable to loss of or gross changes in Purkinje cells. Subtle decreases in the length of Purkinje dendritic branches were apparent in the upper margins in Nfia-null mice relative to wild type (Fig. 4 E). This may reflect reduced maturation of parallel fibers within this region of the ML and the presence of a residual EGL containing CGNs. Finally, S100 immunostaining revealed that the density and distribution of Bergmann glia also were unaltered in Nfia-null mice (data not shown).

\section{CGN axon formation is disrupted in Nfib-null mice}

Perinatal death of $N f i b$ knock-out mice precluded an extensive analysis of CGN differentiation in these animals. However, E18 
A

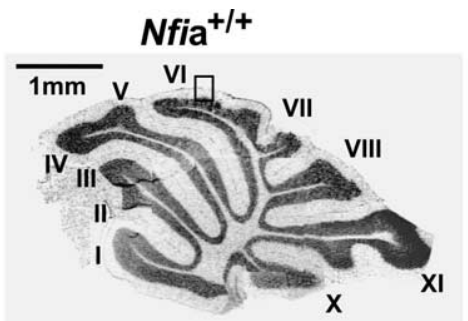

Anterior

Posterior
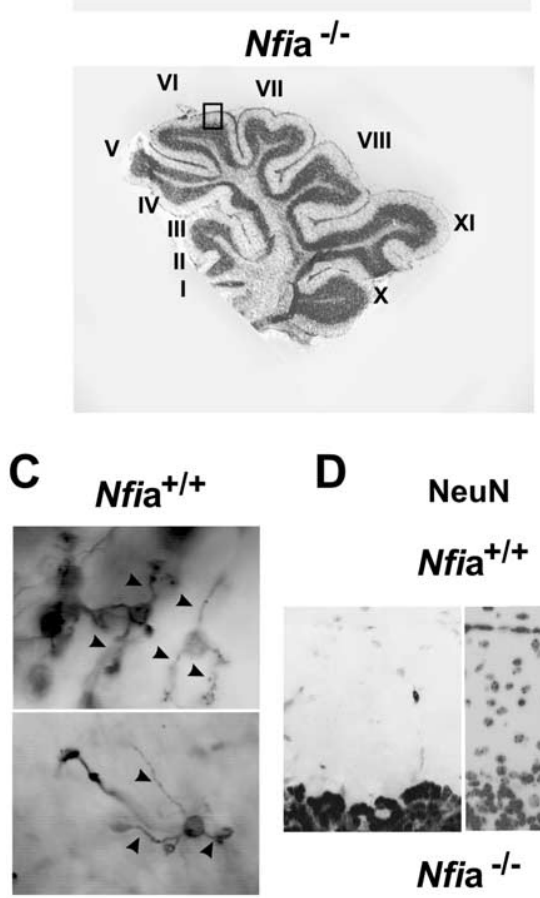

D

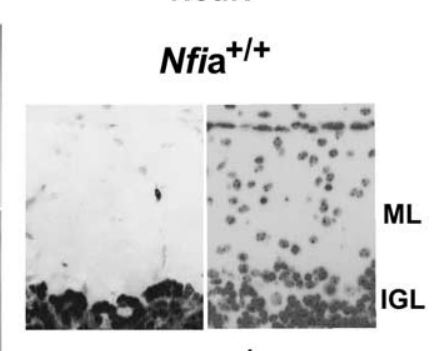

$\mathrm{Nfia}^{-/-}$
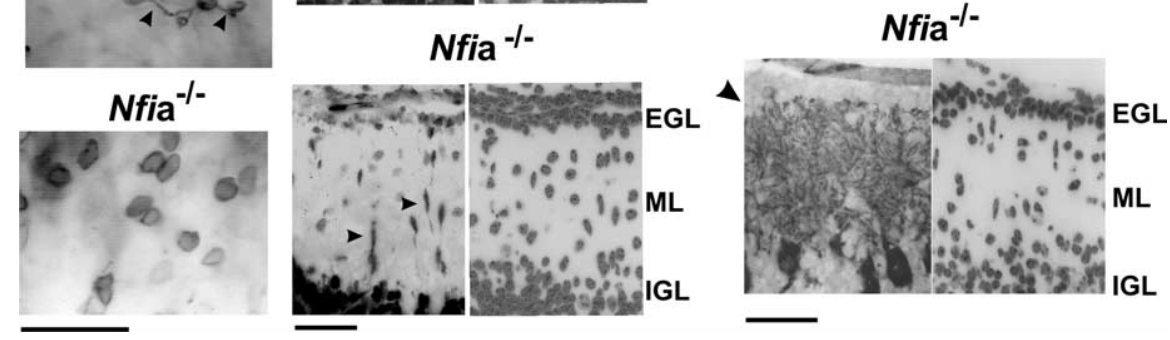

Figure 4. Abnormal cerebellar development in Nfi-null mice. $A$, Bisbenzimide staining of sagittal sections through the vermis of P17 mice showing altered foliation in Nfi mutants. Top, $\mathrm{Nfia}^{+/+}$. Bottom, $\mathrm{Nfia}^{-/-}$. Lobules are labeled with roman numerals. B, Dil-labeled parallel fibers within cerebellar coronal sections from wild-type and Nfia-null animals. Left, Arrowheads indicate parallel fibers within the ML extending away from the Dil crystal inserted at the midline. Axon extension is reduced throughout the cerebellar vermis of Nfia-null mice compared with wild-type mice. Right, Higher magnification of the ML showing dramatically shortened axons in Nfia-null mice. Note the parallel orientation of fibers in wild-type cerebella. Bottom, Numerous disorientated axons (arrowheads) extending toward the IGL and/or meninges are observed only in Nfia-null cerebella. C, Dil-labeled dendritic processes on CGNs within the IGL of the anterior vermis of wild-type (top) and Nfia-null (bottom) mice. Wild-type CGNs exhibited typical claw-shaped dendrites (arrowheads), which were lacking on (GNs within the anterior cerebella of mutant mice. Note that the intensity of Dil staining of CGN cell bodies within the IGL was identical in wild-type and Nfia mutant mice. D, P17 Nfia-null mice exhibit a residual EGL containing differentiating $\left(\mathrm{GNs}\right.$. Left, $\mathrm{NeuN}^{+}$cells within sagittal sections of wild-type and $\mathrm{Nfia}^{-1-}$ mice from lobule VI (regions are indicated by rectangles in $\boldsymbol{A}$ ). Arrowheads indicate ectopic cells within the ML of mutant mice. Right, Bisbenzimide staining of the same sections. $\boldsymbol{E}$, Left, Calbindin immunostaining of Purkinje cells in wild-type and Nfia-null cerebella. The location and densities of these cells were the same in both genotypes. Dendritic processes in Nfia mutant mice were less extensive along their superficial aspect (arrowhead) possibly attributable to reduced parallel fiber extension and residual EGL cells within this region. Right, Bisbenzimide staining of the same sections showing the residual EGL in Nfia mutant cerebellum. Scale bars: $\boldsymbol{B}-\boldsymbol{E}, 50 \mu \mathrm{m}$. All images derive from the vermis of $\mathrm{P} 17$ cerebella.

Nfib-deficient mice were previously reported to have foliation defects within the forming cerebellum (Steele Perkins et al., 2005), possibly reflecting altered early development of granule neurons. We therefore examined whether parallel fiber formation was disturbed in Nfib-null mice using the axonal marker phospho-neurofilament. Immunostaining was greatly reduced within the EGL/ PMZ region in Nfib-deficient mice (Fig. $5)$. This did not reflect a general disruption of CGN differentiation, because NeuroD protein was readily detected in the EGL/PMZ region of both $\mathrm{Nfib}^{+/+}$and $\mathrm{Nifb}^{-1-}$ mice (data not shown). Thus, loss of NFIB expression alters axon formation by CGNs in the early cerebellum. Together, knock-out mouse results indicated that NFI proteins, in particular NFIA and NFIB, are important for normal development of CGNs, including parallel fiber formation within the EGL/PMZ and dendrite formation in the IGL.

NFI regulates the expression of cell adhesion molecules in postmitotic CGNs

The fact that NFI regulation of axon formation occurred in CGN reaggregates suggested that its actions might be mediated by cell adhesion molecules, at least in part. We therefore examined the expression of several cell adhesion and guidance molecules implicated in axonogenesis and/or migration after treatment of CGNs with the NFI dominant repressor. The mRNAs for two of these, $\mathrm{N}$-cadherin and ephrin B1, were markedly downregulated (approximately threefold) in CGN cultures by NFI/EnR, whereas those for several others (ephrin B2, EphB1, slit2, integrin $\beta 1$, and L1) were unaffected (Fig. $6 A$ and data not shown). These findings indicated that ephrin B1 and N-cadherin lie downstream of NFI in differentiating granule neurons.

Based on these results, we determined the expression of ephrin B1 and $\mathrm{N}$-cadherin in CGNs within the developing mouse cerebellum. In P6 mice, ephrin B1 was predominantly localized to the PMZ and ML and also was present in the IGL (Fig. 6B). N-cadherin was detected throughout the cerebellum of P6 mice, including the EGL, ML, and IGL, as well as white matter (Fig. 6B). These expression patterns mirror those reported previously for the two proteins in the developing rat cerebellum (Doherty et al., 1991; MorenoFlores et al., 2002) and are consistent with their functioning throughout different stages of CGN maturation.

We next examined whether the expression of ephrin B1 and $\mathrm{N}$-cadherin in the cerebellum was affected by disruption of $N f i$ genes. Immunostaining for both proteins was reduced in the ML and IGL of P17 cerebella from $\mathrm{Nfia}^{-1-}$ mice relative to wildtype controls (Fig. 6C). Cerebellar expression of another cell adhesion molecule, sialylated-NCAM, was unaltered in Nfia knockout mice (data not shown). Western blotting confirmed that both 


\section{Neurofilament $\mathrm{Nfib}^{+/+}$ $\mathrm{Nfib}^{-1-}$}
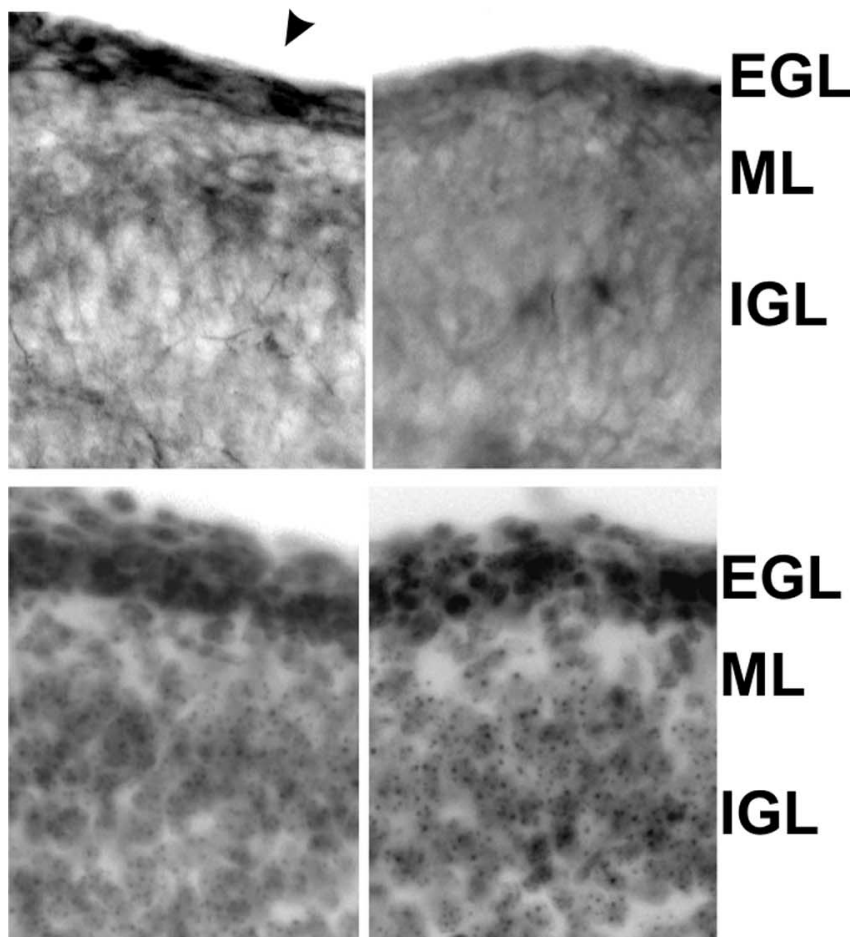

Figure 5. Axon formation is altered in the late embryonic cerebellum of Nfib-null mice. Top, Sagittal sections of E18 cerebella from $\mathrm{Nfib}^{+/+}$and $\mathrm{Nfib}^{-/-}$mice stained for phosphoneurofilament, which is greatly reduced in Nfib mutant mice. The posterior cerebellum is shown. Arrowhead indicates immunoreactive cells within the EGL of wild-type cerebellum. Bottom, Bisbenzimide staining of the same sections. Scale bar, $50 \mu \mathrm{m}$.

ephrin B1 and N-cadherin were substantially reduced in Nfianull mice relative to those from wild-type littermates (Fig. 6D). A dramatic loss of ephrin B1 immunostaining also was observed in the E18 Nfib-null mouse cerebellum (Fig. 6E). The impact of $N f i b$ deficiency on $\mathrm{N}$-cadherin expression could not be determined because immunostaining for this protein was extremely low in both wild-type and mutant cerebella at E18 (data not shown). Together, these results indicated that ephrin $\mathrm{B} 1$ and $\mathrm{N}$-cadherin lie downstream of NFI in differentiating CGNs.

\section{NFI proteins bind to the ephrin $\mathrm{B} 1$ and $\mathrm{N}$-cadherin genes in vivo}

Analysis of the $5^{\prime}$-flanking sequences of the mouse $\mathrm{N}$-cadherin and ephrin $\mathrm{B} 1$ genes identified multiple consensus binding sites for NFI upstream of exon 1 (Fig. 7A). ChIP assays demonstrated that NFI was bound to these 5 '-flanking sequences of both genes in purified CGN cultures (Fig. 7B). Furthermore, ChIP assays confirmed in vivo association of NFI with these promoters in the intact P15 mouse cerebellum, which is highly enriched in CGNs (Fig. 7C). Thus, NFI is present on the $\mathrm{N}$-cadherin and ephrin $\mathrm{B} 1$ promoters in vivo, and its transactivation ability is required for expression of these genes in mouse CGNs.

Inhibitors of ephrin $\mathrm{B} 1$ and $\mathrm{N}$-cadherin alter axon formation, migration, and dendritogenesis by CGNs. Both N-cadherin and ephrin B1 have been implicated in axonogenesis, neuronal migration, and dendritogenesis (Barami et al., 1994; Riehl et al.,
1996; Gao et al., 1999; Palmer and Klein, 2003; Zhu and Luo, 2004). Thus, these cell adhesion molecules were excellent candidates as mediators of NFI actions during CGN differentiation. Although surfaces containing ephrin B1 or N-cadherin can accelerate neurite outgrowth by CGNs (Doherty et al., 1991; MorenoFlores et al., 2002), a specific requirement for either protein in axon and dendrite formation by these cells has not been demonstrated. We therefore used functional inhibitors to directly examine the roles of ephrin B1 and N-cadherin in mediating NFI regulation of CGN differentiation. We tested the effects of soluble, unclustered ephrin B1 (ephrin B1-Fc), an antagonist of ephrin B actions (Davis et al., 1994), as well as peptide antagonists of homotypic binding to the N-cadherin extracellular domain 1 (Williams et al., 2000a,b) and an N-cadherin blocking antibody (GC-4) (Volk and Geiger, 1984).

In reaggregate cultures, all three inhibitors altered migration and axon extension by CGNs on laminin. CGN migration was essentially blocked in the presence of soluble ephrin B1-Fc (Fig. $8 \mathrm{~A}$ ). In addition, axon extension and density were inhibited 5.4and 3.3-fold, respectively ( $p<0.001$ for each), with axons being highly fasciculated (Fig. $8 \mathrm{~B}$ ). In contrast, addition of the soluble form of the ephrin receptor EphB1 did not significantly alter axons or migration (data not shown). N-cadherin antagonist peptide also markedly impaired CGN migration and reduced both the length and number of axons extending from reaggregates approximately fivefold and threefold, respectively $(p<$ 0.001 ) (Fig. $8 C, D$ ). The blocking $\mathrm{N}$-cadherin antibody inhibited migration and produced a distinct phenotype for axon extension, with the axons losing their radial orientation and showing hyperfasciculation (Fig. $8 E, F$ ). These differences between $\mathrm{N}$-cadherin functional blockers may reflect distinct mechanisms of inhibition.

Transwell assays were used to determine the importance of $\mathrm{N}$-cadherin and ephrin B in CGN migration per se. Using dissociated cell cultures, $\mathrm{N}$-cadherin blocking peptides inhibited CGN migration by $\sim 50 \%(p<0.001)$, similar to that observed with the NFI dominant repressor. In contrast, ephrin B1-Fc had no effect on CGN migration under these conditions (data not shown). Because migration assays used dissociated CGNs, it was possible that endogenous ephrin B function was masked by reduced cell-cell contact and ephrin-Eph trans interactions. We therefore examined whether ephrin B1-Fc affected CGN migration in the presence of homotypic cell contacts using reaggregate cultures. Under these conditions, soluble ephrin B1-Fc caused a partial reduction of CGN migration $(\sim 20 \%$; $p<0.05)$ compared with NFI/EnR, which inhibited this process by $50 \%$ (data not shown). Thus, both N-cadherin and ephrin B contribute to NFI regulation of CGN migration.

Finally, cell adhesion molecule inhibitors also suppressed dendrite formation by dissociated CGN cultures (Fig. 8G,H), with $\mathrm{N}$-cadherin peptide antagonists being more effective. Both the number of dendritic processes as well as their lengths were inhibited. Soluble EphB1-Fc had no effect on dendrite extension (Fig. 8G).

\section{$\mathrm{N}$-cadherin and ephrin B function in situ}

The preceding cell culture studies strongly implicated ephrin B and N-cadherin as critical mediators of NFI actions in axon formation, migration, and dendritogenesis in CGNs. We therefore addressed whether they regulated these events in situ using cerebellar slices infected with GFP-expressing retrovirus. Both ephrin $\mathrm{B} 1-\mathrm{Fc}$ and $\mathrm{N}$-cadherin peptides inhibited CGN egress from the EGL to the IGL in sagittal slices (Fig. 9A,B). In coronal slices, soluble ephrin B1-Fc repressed extension of newly forming axons 
A

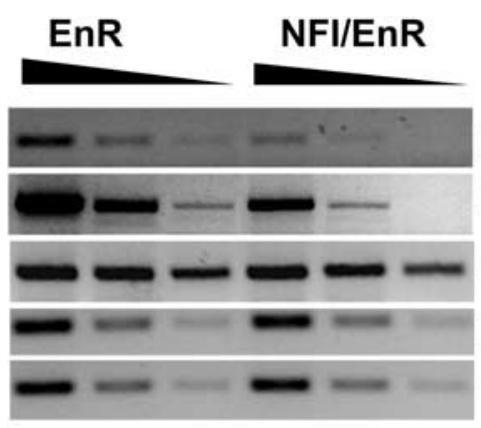

B

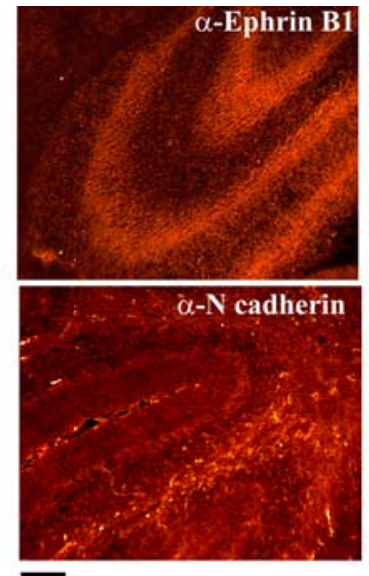

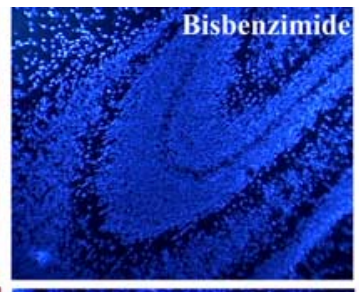

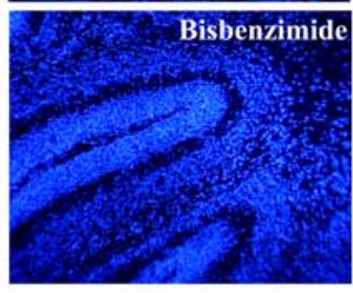



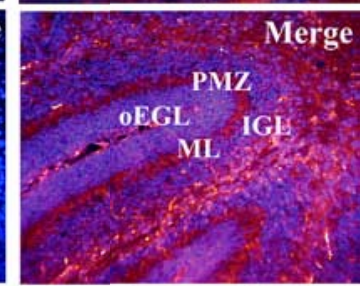

C

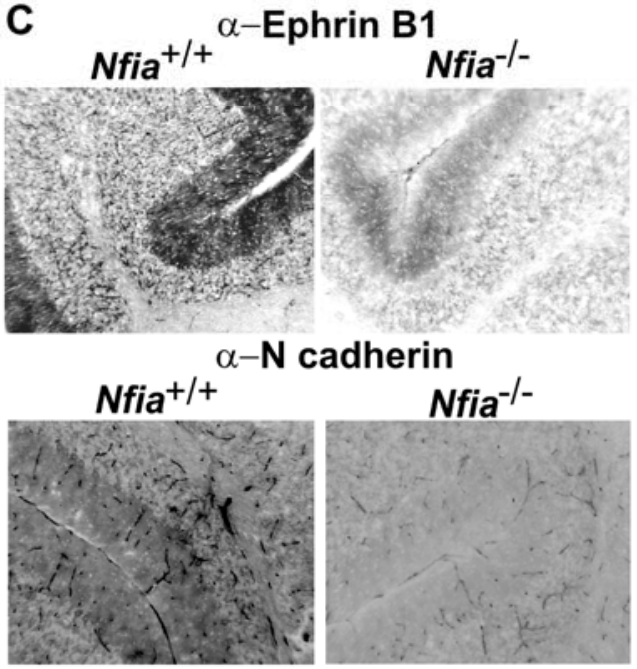

D
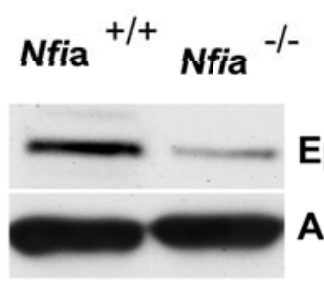

\section{Ephrin B1}

\section{Actin}


\section{E}

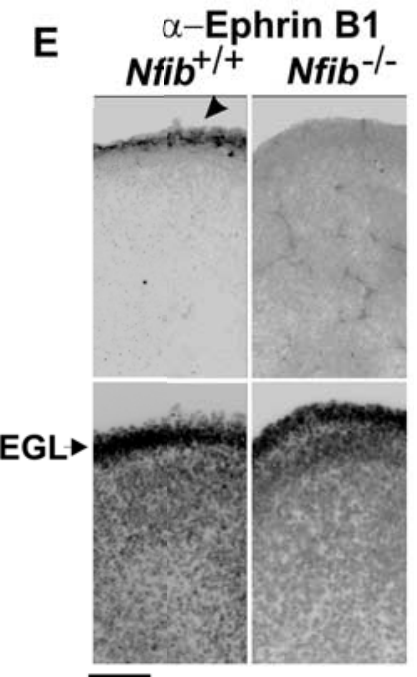

Figure 6. Expression of cell adhesion molecules is regulated by NFI in CGNs. A, Ephrin B1 and N-cadherin transcripts are specifically reduced by the NFI dominant repressor in CGNs. Semiquantitative RT-PCR analysis of cell adhesion or guidance molecule mRNAs in CGN cultures transduced with NFI/EnR or EnR lentiviruses. Samples were analyzed using threefold serial dilutions. 185 ribosomal RNA was assayed as a loading control. B, Immunostaining for ephrin B1 (top) and N-cadherin (bottom) in the vermis of P6 mouse cerebella. oEGL, Outer EGL region. C, Cell adhesion molecule immunostaining is reduced in Nfia mutant mice. Sagittal sections through the vermis of P17 Nfia ${ }^{+/+}$and $\mathrm{Nfia}^{-/-}$mice were stained with antibodies against ephrin B1 (top) and $\mathrm{N}$-cadherin (bottom). $\boldsymbol{D}$, Western blot analysis of ephrin B1 and N-cadherin in mouse cerebella showing reduced expression of these proteins in Nfia-deficient mice. $\boldsymbol{E}$, Ephrin B1 immunostaining (top) is reduced in $\mathrm{E} 18 \mathrm{Nfib}^{-/-}$mouse cerebellum relative to $\mathrm{Nfib}^{+/+}$controls. The arrowhead indicates labeled cells within the EGL of wild-type mice. Bottom, Bisbenzimide staining of the same sections. Scale bars, $50 \mu \mathrm{m}$.

A

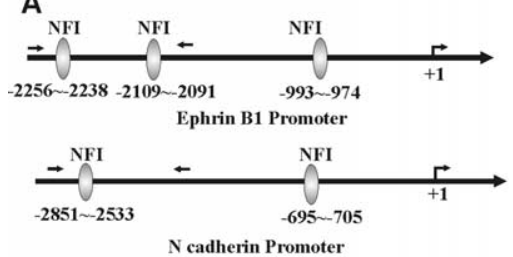

B

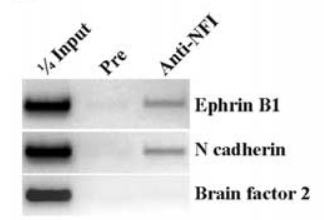

Figure 7. In vivo binding of NFI to cell adhesion molecule promoters in postmitotic CGNs. A, Locations of consensus NFI binding sites within the mouse ephrin $B 1$ and $N$-cadherin promoters. The approximate positions of $P C R$ primers within the $5^{\prime}$ regions for ChIP assays are indicated by arrows. $B$, ChIP assay showing that NFI proteins are bound in vivo to the ephrin B1 and N-cadherin promoter regions in 6 DIV CGN cell cultures. C, NFI binds to the ephrin B1 and N-cadherin promoters in intact mouse cerebellar tissue. ChIP assay using nuclei prepared from P15 cerebella, $>85 \%$ of which derive from CGNs based on NeuN and NeuroD immunostaining. Mouse brain factor 2 genomic sequences were used as a negative control. Pre, Preimmune serum.

(Fig. 9C), decreasing their average length approximately fourfold $(p<0.001)$. Similarly, N-cadherin antagonist peptides inhibited CGN axon formation (Fig. 9D) approximately threefold $(p<0.001)$. Furthermore, both inhibitors altered the parallel orientation of newly extending axons (Fig. 9C,D). Antagonism of $\mathrm{N}$-cadherin caused a more dramatic defasciculation that was sim-
C

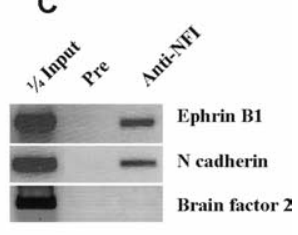

ilar in extent to that observed with the NFI dominant repressor (Fig. 3A).

Dendrite formation by CGNs within the IGL of cerebellar slices also was disrupted by these antagonists (Fig. 9E,F). Both $\mathrm{N}$-cadherin peptides and ephrin $\mathrm{B} 1-\mathrm{Fc}$ reduced the number of primary dendritic arborizations approximately threefold ( $p<0.01$ ), and these processes tended to be thinner.

\section{Discussion}

Previous studies involving knock-out mice have directly implicated NFIA and NFIB in CNS development, in particular in the formation of midline glia (das Neves et al., 1999; Shu et al., 2003; Steele Perkins et al., 2005). Recently, NFIA also was found to be required for gliogenesis within the developing chick spinal cord (Deneen et al., 2006). NFIB also has been directly implicated in hippocampal and pons development (Steele Perkins et al., 2005). However, knowledge of the broader 
functions and targets for NFI proteins in developing neurons has remained limited. Our cell culture, in situ and Nfi knock-out studies indicate that NFI family members are central transcriptional regulators of CGN development, their function being important for several major aspects of their postmitotic maturation: axon formation in the PMZ, migration, and dendrite formation within the IGL. Furthermore, we demonstrated previously that NFI directly regulates expression of the extrasynaptic neurotransmitter receptor subunit Gabra6, present in the IGL (Wang et al., 2004). Thus, a single transcription factor family can act during postmitotic neuronal differentiation during multiple maturation stages.

Another finding is that cell adhesion molecules are an important class of NFI targets and downstream mediators in maturing CGNs. This observation helps to explain how NFI regulates diverse aspects of CGN development. N-cadherin and ephrin B1 appear to have broad functions as cell adhesion molecules in developing neurons (Barami et al., 1994; Riehl et al., 1996; Gao et al., 1999; Palmer and Klein, 2003; Zhu and Luo, 2004; Halloran and Wolman, 2006). In CGN cultures, both proteins can promote axon formation when used as substrata for outgrowth, and ephrin B1 stimulates dendrite extension as a surface ligand (Doherty et al., 1991; Moreno-Flores et al., 2002). Also, ephrin $\mathrm{B}$ reverse signaling interferes in vitro with the chemoattractive effect of stromal cellderived factor-1 (SDF-1) (Lu et al., 2004). The present inhibitor studies extend these previous findings, indicating direct involvement of both endogenous ephrin B and $\mathrm{N}$-cadherin specifically in parallel fiber extension, dendritogenesis, and migratory behavior by CGNs both in vitro and in situ. The expression of ephrin B1 within the EGL/PMZ, $\mathrm{ML}$, and IGL of the mouse cerebellum is consistent with these diverse functions. Similarly, $\mathrm{N}$-cadherin has been associated with growth cones derived from extending axons of CGNs (Nakai and Kamiguchi, 2002) as well as with synaptic glomeruli within the granule cell layer of the mouse cerebellum (Fannon and Colman, 1996).

Local cellular interactions are critical for different stages of CGN development. For example, homotypic cell-cell contacts are important for proliferation of CGN progenitors (Gao et al., 1991) and for early differentiation and migration from the EGL (Gao and Hatten, 1993; Lu et al., 2004). Furthermore, newly forming axons within the PMZ form fascicles of parallel fibers that involve axonal contacts between neighboring CGNs (Altman, 1972; Berglund et al., 1999). Cell surface proteins play a central role in these cell contact-dependent events by promoting intercellular signaling and cell adhesion (Berglund et al., 1999; Solecki et al., 2001; Lu et al., 2004).

NFI regulation of axon formation was observed under condi- tions of homotypic cell contact, consistent with a role for cell adhesion molecules in mediating this process. Inhibitor studies using cerebellar slices indicated that NFI influences parallel fiber orientation/fasciculation by promoting the expression of ephrin $\mathrm{B} 1$ and $\mathrm{N}$-cadherin expression, at least in part. This likely involves trans interactions between $\mathrm{N}$-cadherin monomers or ephrin B1/ Eph proteins present on neighboring CGN axons. Inhibition of $\mathrm{N}$-cadherin produced a more dramatic disorganization of parallel fiber orientation, suggesting a more primary role as an NFI mediator of axon guidance. Contactin-1 also was previously implicated in parallel fiber fasciculation (Berglund et al., 1999). Thus, multiple cell adhesion molecules appear to cooperate in controlling the orientation of parallel fibers. In addition to fasciculation, our results indicate that the ability of CGNs to extend parallel fibers per se also is dependent on homotypic trans interactions involving NFI regulation of both ephrin B1 and $\mathrm{N}$-cadherin.

In contrast to the effects on axon outgrowth, NFI, ephrin B, and $\mathrm{N}$-cadherin regulate dendrite formation in dissociated CGN 
A

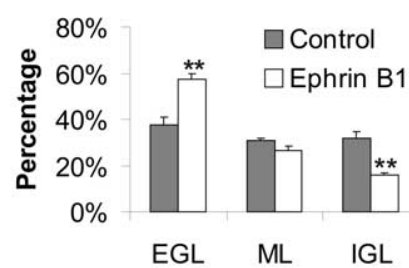

C
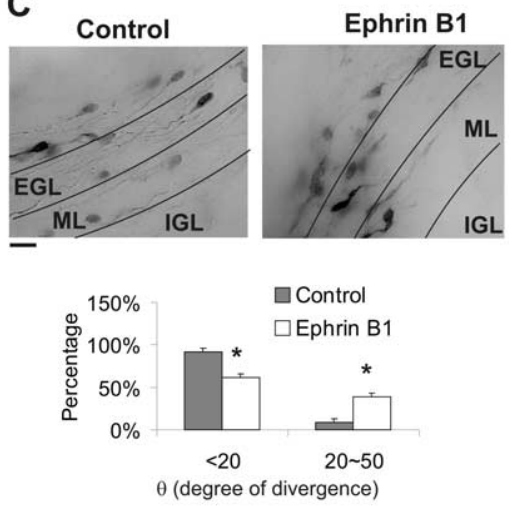

E



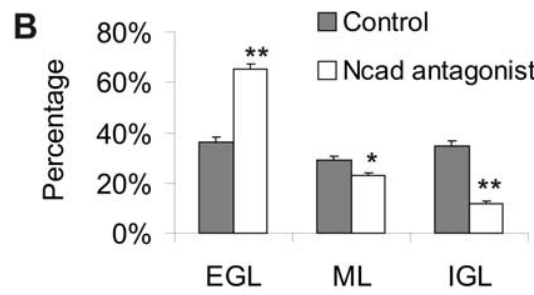

D Control
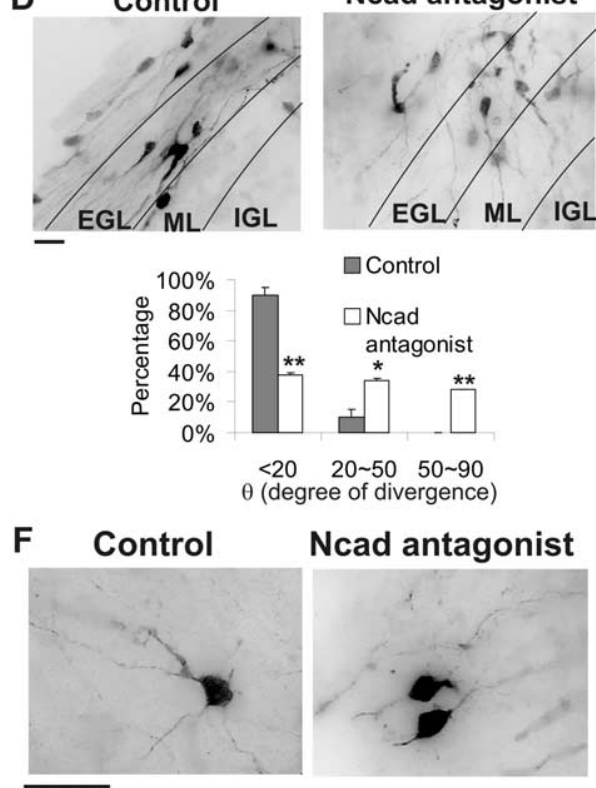

Figure 9. Cell adhesion molecule inhibitors disrupt differentiation of CGNs in situ. $A, B$, CGN radial migration is inhibited by cell adhesion molecule antagonists. Cerebellar slices were transduced with GFP retroviruses and treated with $50 \mu \mathrm{g} / \mathrm{ml}$ ephrinB1-Fc, $400 \mu \mathrm{g} / \mathrm{ml} \mathrm{N}$-cadherin inhibitor peptides, or control reagents for $60 \mathrm{~h}$. Distributions of viral-transduced GFP ${ }^{+}$cells within different cerebellar layers are shown. Both inhibitors significantly reduced CGN migration relative to controls. ${ }^{*} p<0.05$; ${ }^{* *} p<$ 0.01. C, D, Top, Antagonists inhibit parallel fiber extension and induce axon misorientation. GFP ${ }^{+}$parallel fibers in the PMZ/ML region of coronal slices treated with $50 \mu \mathrm{g} / \mathrm{ml}$ ephrinB1-Fc or $400 \mu \mathrm{g} / \mathrm{ml} \mathrm{N}$-cadherin inhibitor peptides for $48 \mathrm{~h}$. Labeled cells lying outside the indicated layers derive from an adjacent EGL (see legend to Fig. 3B). Bottom, The orientation of GFP ${ }^{+}$axons was significantly altered by the soluble inhibitors relative to controls. ${ }^{*} p<0.01 ;{ }^{* *} p<0.001$. $\theta$, Angle of divergence from the parallel orientation for $\mathrm{GFP}^{+}$axons, expressed in degrees. $\boldsymbol{E}, \boldsymbol{F}$, Antagonists inhibit extension of GFP-labeled dendrites from retroviraltransduced CGNs within the IGL of cerebellar slices. Cultures were treated with either ephrinB1-Fc (E) or N-cadherin antagonist peptides $(\boldsymbol{F})$ or control reagents for $60 \mathrm{~h}$.

cultures. This could reflect homotypic cellular interactions operating under these conditions (e.g., cell contacts involving extended axons) or, alternatively, cell autonomous functions of these cell adhesion molecules. For example, cis interactions have been observed between ephrin ligands and Eph receptors as well as between N-cadherin monomers (Takeda et al., 1999; Shan et al., 2000; Yin et al., 2004; Marquardt et al., 2005) (see also below).

In addition to process formation, NFI also regulates CGN migration through ephrin B1 and N-cadherin. Ephrin B reverse signaling was previously implicated in CGN egress from the EGL via its antagonism of SDF-1 (Lu et al., 2004), which is a CGN chemoattractant released by the meninges that prevents their premature migration from the EGL (Ma et al., 1999). In addition to this permissive function, our findings indicate that ephrin $B$ also can directly promote CGN migration to some extent under conditions of homotypic cell contact, such as those present within the EGL. Inhibitor studies also indicated that $\mathrm{N}$-cadherin has a prominent role in mediating NFI regulation of CGN migration. Facilitation of CGN migratory behavior by endogenous $\mathrm{N}$-cadherin has not been reported previously. One distinction between these two mediators is the apparent requirement for trans signaling in the case of ephrin B.

Studies of NFI-regulated axon extension, migration, and dendritogenesis in cell culture were preformed on a laminin surface and thus involved integrin $\beta 1$ dependent mechanisms. Integrin $\beta 1$ mRNA is expressed throughout CGN development within the postnatal mouse cerebellum (Blaess et al., 2004). Integrin $\beta 1$ has been implicated in several aspects of CGN development, including progenitor proliferation (Blaess et al., 2004), axon extension (Mercado et al., 2004), and migration (Fishman and Hatten, 1993; Thelen et al., 2002; Lauro et al., 2006). Interestingly, both ephrins and $\mathrm{N}$-cadherin can interact in cis with integrin $\beta 1$ pathways during axon extension (Arregui et al., 2000; Nakamoto et al., 2004) as well as cell migration (Li et al., 2000; Huynh-Do et al., 2002). Thus, NFI may promote axon formation, migration, and dendritogenesis through signaling interactions between ephrin B1/N-cadherin and integrin $\beta 1$. Significantly, cell-autonomous interactions between integrin $\beta 1$ and $\mathrm{N}$ cadherin were shown recently to regulate dendritic architecture in retinal ganglion cells (Marrs et al., 2006). Similar cellautonomous, cis interactions may account for the stimulation of dendrite formation in dissociated cultures by NFI, N-cadherin, and ephrin B.

Gene knock-out mice indicate that both NFIA and NFIB are important for proper differentiation of CGNs. Furthermore, downregulation of $\mathrm{N}$-cadherin and/or ephrin B1 in Nfi-null mice suggests that loss of both proteins contributes to these alterations in CGN differentiation. Nfia-deficient mice exhibited disrupted parallel fiber formation and orientation as well as CGN dendritogenesis, consistent with cell culture and in situ studies using the NFI dominant repressor. Radial migration also was incomplete by P17 in these mice, which may reflect inhibition of migratory behavior and/or earlier differentiation events mediated by ephrin B1/N-cadherin such as parallel fiber extension. Alterations in CGN proliferation, growth arrest, or onset of early differentiation attributable to Nfia deficiency also cannot be ruled out. However, this is not supported by the lack of effect of NFI/EnR on BrdU incorporation in CGN cell cultures and by the unaltered expression of the early differentiation markers NeuroD and NeuN in NFI/EnR-expressing CGNs and in Nfia-null mice. There was also no evidence of residual CGN progenitors in P17 Nfia-null mice. It is possible that alterations in other cell types also may contribute to the cerebellar phenotype in $N f i$ gene knock-out mice (Mathis et al., 2003). For example, immunostaining for both $\mathrm{N}$-cadherin and ephrin B1 were broadly diminished in the cerebellum of Nfia-null mice. Finally, the disruption of axonal marker expression in the EGL of Nfib-null mice indicates that this family member also is critical for normal parallel fiber formation in the early forming cerebellum.

In addition to its role in CGN differentiation, loss of NFIA results in reduced formation of midline glia in the mouse fore- 
brain (Shu et al., 2003). Furthermore, this factor inhibits neurogenesis via Hes5 (hairy and enhancer of split 5) in ventricular zone progenitors within the embryonic chick spinal cord and promotes their gliogenesis and also directs subsequent differentiation of spinal astrocytic precursors (Deneen et al., 2006). Thus, NFIA and its family members appear to be versatile regulators in the developing CNS, having diverse functions and targets that promote the differentiation of distinct neural cell types depending on the developmental context.

\section{References}

Altman J (1972) Postnatal development of the cerebellar cortex in the rat. 3. Maturation of the components of the granular layer. J Comp Neurol 145:465-513.

Arregui C, Pathre P, Lilien J, Balsamo J (2000) The nonreceptor tyrosine kinase fer mediates cross-talk between $\mathrm{N}$-cadherin and betal-integrins. J Cell Biol 149:1263-1274.

Aruga J, Minowa O, Yaginuma H, Kuno J, Nagai T, Noda T, Mikoshiba K (1998) Mouse Zicl is involved in cerebellar development. J Neurosci 18:284-293.

Aruga J, Inoue T, Hoshino J, Mikoshiba K (2002) Zic2 controls cerebellar development in cooperation with Zic1. J Neurosci 22:218-225.

Barami K, Kirschenbaum B, Lemmon V, Goldman SA (1994) N-cadherin and $\mathrm{Ng}$-CAM/8D9 are involved serially in the migration of newly generated neurons into the adult songbird brain. Neuron 13:567-582.

Ben-Arie N, Bellen HJ, Armstrong DL, McCall AE, Gordadze PR, Guo Q, Matzuk MM, Zoghbi HY (1997) Math1 is essential for genesis of cerebellar granule neurons. Nature 390:169-172.

Berglund EO, Murai KK, Fredette B, Sekerkova G, Marturano B, Weber L, Mugnaini E, Ranscht B (1999) Ataxia and abnormal cerebellar microorganization in mice with ablated contactin gene expression. Neuron 24:739-750.

Bix GJ, Clark GD (1998) Platelet-activating factor receptor stimulation disrupts neuronal migration in vitro. J Neurosci 18:307-318.

Blaess S, Graus-Porta D, Belvindrah R, Radakovits R, Pons S, LittlewoodEvans A, Senften M, Guo H, Li Y, Miner JH, Reichardt LF, Muller U (2004) $\beta 1$-integrins are critical for cerebellar granule cell precursor proliferation. J Neurosci 24:3402-3412.

Chaudhry AZ, Lyons GE, Gronostajski RM (1997) Expression patterns of the four nuclear factor I genes during mouse embryogenesis indicate a potential role in development. Dev Dyn 208:313-325.

das Neves L, Duchala CS, Tolentino-Silva F, Haxhiu MA, Colmenares C, Macklin WB, Campbell CE, Butz KG, Gronostajski RM (1999) Disruption of the murine nuclear factor I-A gene (Nfia) results in perinatal lethality, hydrocephalus, and agenesis of the corpus callosum. Proc Natl Acad Sci USA 96:11946-11951.

Davis S, Gale NW, Aldrich TH, Maisonpierre PC, Lhotak V, Pawson T, Goldfarb M, Yancopoulos GD (1994) Ligands for EPH-related receptor tyrosine kinases that require membrane attachment or clustering for activity. Science 266:816-819.

Deneen B, Ho R, Lukaszewicz A, Hochstim CJ, Gronostajski RM, Anderson DJ (2006) The transcription factor NFIA controls the onset of gliogenesis in the developing spinal cord. Neuron 52:953-968.

Doherty P, Rowett LH, Moore SE, Mann DA, Walsh FS (1991) Neurite outgrowth in response to transfected N-CAM and N-cadherin reveals fundamental differences in neuronal responsiveness to CAMs. Neuron $6: 247-258$.

Fannon AM, Colman DR (1996) A model for central synaptic junctional complex formation based on the differential adhesive specificities of the cadherins. Neuron 17:423-434.

Fishman RB, Hatten ME (1993) Multiple receptor systems promote CNS neural migration. J Neurosci 13:3485-3495.

Galipeau J, Li H, Paquin A, Sicilia F, Karpati G, Nalbantoglu J (1999) Vesicular stomatitis virus $\mathrm{G}$ pseudotyped retrovector mediates effective in vivo suicide gene delivery in experimental brain cancer. Cancer Res 59:2384-2394.

Gao PP, Yue Y, Cerretti DP, Dreyfus C, Zhou R (1999) Ephrin-dependent growth and pruning of hippocampal axons. Proc Natl Acad Sci USA 96:4073-4077.

Gao WO, Heintz N, Hatten ME (1991) Cerebellar granule cell neurogenesis is regulated by cell-cell interactions in vitro. Neuron 6:705-715.
Gao WQ, Hatten ME (1993) Neuronal differentiation rescued by implantation of Weaver granule cell precursors into wild-type cerebellar cortex. Science 260:367-369.

Gazit R, Krizhanovsky V, Ben-Arie N (2004) Math1 controls cerebellar granule cell differentiation by regulating multiple components of the Notch signaling pathway. Development 131:903-913.

Gronostajski RM (2000) Roles of the NFI/CTF gene family in transcription and development. Gene 249:31-45.

Grunder A, Ebel TT, Mallo M, Schwarzkopf G, Shimizu T, Sippel AE, Schrewe H (2002) Nuclear factor I-B (Nfib) deficient mice have severe lung hypoplasia. Mech Dev 112:69-77.

Halloran MC, Wolman MA (2006) Repulsion or adhesion: receptors make the call. Curr Opin Cell Biol 18:533-540.

Hirotsune S, Fleck MW, Gambello MJ, Bix GJ, Chen A, Clark GD, Ledbetter DH, McBain CJ, Wynshaw-Boris A (1998) Graded reduction of Pafahlb1 (Lis1) activity results in neuronal migration defects and early embryonic lethality. Nat Genet 19:333-339.

Huynh-Do U, Vindis C, Liu H, Cerretti DP, McGrew JT, Enriquez M, Chen J, Daniel TO (2002) Ephrin-B1 transduces signals to activate integrinmediated migration, attachment and angiogenesis. J Cell Sci 115:3073-3081.

Jensen P, Smeyne R, Goldowitz D (2004) Analysis of cerebellar development in math1 null embryos and chimeras. J Neurosci 24:2202-2211.

Lauro C, Catalano M, Trettel F, Mainiero F, Ciotti MT, Eusebi F, Limatola C (2006) The chemokine CX3CL1 reduces migration and increases adhesion of neurons with mechanisms dependent on the betal integrin subunit. J Immunol 177:7599-7606.

Li H, Leung TC, Hoffman S, Balsamo J, Lilien J (2000) Coordinate regulation of cadherin and integrin function by the chondroitin sulfate proteoglycan neurocan. J Cell Biol 149:1275-1288.

Li S, Qiu F, Xu A, Price SM, Xiang M (2004) Barhll regulates migration and survival of cerebellar granule cells by controlling expression of the neurotrophin-3 gene. J Neurosci 24:3104-3114.

Lu Q, Sun EE, Flanagan JG (2004) Analysis of PDZ-RGS3 function in ephrin-B reverse signaling. Methods Enzymol 390:120-128.

Ma Q, Jones D, Springer TA (1999) The chemokine receptor CXCR4 is required for the retention of $\mathrm{B}$ lineage and granulocytic precursors within the bone marrow microenvironment. Immunity 10:463-471.

Marquardt T, Shirasaki R, Ghosh S, Andrews SE, Carter N, Hunter T, Pfaff SL (2005) Coexpressed EphA receptors and ephrin-A ligands mediate opposing actions on growth cone navigation from distinct membrane domains. Cell 121:127-139.

Marrs GS, Honda T, Fuller L, Thangavel R, Balsamo J, Lilien J, Dailey ME, Arregui C (2006) Dendritic arbors of developing retinal ganglion cells are stabilized by beta 1-integrins. Mol Cell Neurosci 32:230-241.

Mathis C, Collin L, Borrelli E (2003) Oligodendrocyte ablation impairs cerebellum development. Development 130:4709-4718.

Mercado ML, Nur-e-Kamal A, Liu HY, Gross SR, Movahed R, Meiners S (2004) Neurite outgrowth by the alternatively spliced region of human tenascin-C is mediated by neuronal $\alpha 7 \beta 1$ integrin. J Neurosci 24:238-247.

Millen KJ, Hui CC, Joyner AL (1995) A role for En-2 and other murine homologues of Drosophila segment polarity genes in regulating positional information in the developing cerebellum. Development 121:3935-3945.

Miyata T, Maeda T, Lee JE (1999) NeuroD is required for differentiation of the granule cells in the cerebellum and hippocampus. Genes Dev 13:1647-1652.

Moreno-Flores MT, Martin-Aparicio E, Avila J, Diaz-Nido J, Wandosell F (2002) Ephrin-B1 promotes dendrite outgrowth on cerebellar granule neurons. Mol Cell Neurosci 20:429-446.

Nakai Y, Kamiguchi H (2002) Migration of nerve growth cones requires detergent-resistant membranes in a spatially defined and substratedependent manner. J Cell Biol 159:1097-1108.

Nakamoto T, Kain KH, Ginsberg MH (2004) Neurobiology: new connections between integrins and axon guidance. Curr Biol 14:R121-R123.

Palmer A, Klein R (2003) Multiple roles of ephrins in morphogenesis, neuronal networking, and brain function. Genes Dev 17:1429-1450.

Powell SK, Rivas RJ, Rodriguez-Boulan E, Hatten ME (1997) Development of polarity in cerebellar granule neurons. J Neurobiol 32:223-236.

Riehl R, Johnson K, Bradley R, Grunwald GB, Cornel E, Lilienbaum A, Holt CE (1996) Cadherin function is required for axon outgrowth in retinal ganglion cells in vivo. Neuron 17:837-848. 
Ronn LC, Ralets I, Hartz BP, Bech M, Berezin A, Berezin V, Moller A, Bock E (2000) A simple procedure for quantification of neurite outgrowth based on stereological principles. J Neurosci Methods 100:25-32.

Schwartz PM, Borghesani PR, Levy RL, Pomeroy SL, Segal RA (1997) Abnormal cerebellar development and foliation in BDNF-/- mice reveals a role for neurotrophins in CNS patterning. Neuron 19:269-281.

Shan WS, Tanaka H, Phillips GR, Arndt K, Yoshida M, Colman DR, Shapiro L (2000) Functional cis-heterodimers of N- and R-cadherins. J Cell Biol 148:579-590.

Shu T, Butz KG, Plachez C, Gronostajski RM, Richards LJ (2003) Abnormal development of forebrain midline glia and commissural projections in Nfia knock-out mice. J Neurosci 23:203-212.

Soha JM, Kim S, Crandall JE, Vogel MW (1997) Rapid growth of parallel fibers in the cerebella of normal and staggerer mutant mice. J Comp Neurol 389:642-654

Solecki DJ, Liu XL, Tomoda T, Fang Y, Hatten ME (2001) Activated Notch2 signaling inhibits differentiation of cerebellar granule neuron precursors by maintaining proliferation. Neuron 31:557-568.

Steele Perkins G, Butz KG, Lyons GE, Zeichner-David M, Kim HJ, Cho MI, Gronostajski RM (2003) Essential role for NFI-C/CTF transcriptionreplication factor in tooth root development. Mol Cell Biol 23:1075-1084.

Steele Perkins G, Plachez C, Butz KG, Yang G, Bachurski CJ, Kinsman SL, Litwack ED, Richards LJ, Gronostajski RM (2005) The transcription factor gene Nfib is essential for both lung maturation and brain development. Mol Cell Biol 25:685-698.

Swanson DJ, Tong Y, Goldowitz D (2005) Disruption of cerebellar granule cell development in the Pax6 mutant, Sey mouse. Brain Res Dev Brain Res 160:176-193.

Takeda H, Shimoyama Y, Nagafuchi A, Hirohashi S (1999) E-cadherin functions as a cis-dimer at the cell-cell adhesive interface in vivo. Nat Struct Biol 6:310-312.

Thelen K, Kedar V, Panicker AK, Schmid RS, Midkiff BR, Maness PF (2002) The neural cell adhesion molecule $\mathrm{L} 1$ potentiates integrin-dependent cell migration to extracellular matrix proteins. J Neurosci 22:4918-4931.

Tomoda T, Bhatt RS, Kuroyanagi H, Shirasawa T, Hatten ME (1999) A mouse serine/threonine kinase homologous to C. elegans UNC51 functions in parallel fiber formation of cerebellar granule neurons. Neuron 24:833-846.
Volk T, Geiger B (1984) A 135-kd membrane protein of intercellular adherens junctions. EMBO J 3:2249-2260.

Wang W, Stock RE, Gronostajski RM, Wong YW, Schachner M, Kilpatrick DL (2004) A role for nuclear factor I in the intrinsic control of cerebellar granule neuron gene expression. J Biol Chem 279:53491-53497.

Wang W, Qu Q, Smith FI, Kilpatrick DL (2005) Self-inactivating lentiviruses: versatile vectors for quantitative transduction of cerebellar granule neurons and their progenitors. J Neurosci Methods 149:144-153.

Weyer A, Schilling K (2003) Developmental and cell type-specific expression of the neuronal marker NeuN in the murine cerebellum. J Neurosci Res 73:400-409.

Williams E, Williams G, Gour BJ, Blaschuk OW, Doherty P (2000a) A novel family of cyclic peptide antagonists suggests that $\mathrm{N}$-cadherin specificity is determined by amino acids that flank the HAV motif. J Biol Chem 275:4007-4012.

Williams EJ, Williams G, Gour B, Blaschuk O, Doherty P (2000b) INP, a novel $\mathrm{N}$-cadherin antagonist targeted to the amino acids that flank the HAV motif. Mol Cell Neurosci 15:456-464.

Yamasaki T, Kawaji K, Ono K, Bito H, Hirano T, Osumi N, Kengaku M (2001) Pax6 regulates granule cell polarization during parallel fiber formation in the developing cerebellum. Development 128:3133-3144.

Yang XW, Wynder C, Doughty ML, Heintz N (1999) BAC-mediated genedosage analysis reveals a role for Zipro1 (Ru49/Zfp38) in progenitor cell proliferation in cerebellum and skin. Nat Genet 22:327-335.

Yin Y, Yamashita Y, Noda H, Okafuji T, Go MJ, Tanaka H (2004) EphA receptor tyrosine kinases interact with co-expressed ephrin-A ligands in cis. Neurosci Res 48:285-296.

Zhang L, Goldman JE (1996) Generation of cerebellar interneurons from dividing progenitors in white matter. Neuron 16:47-54.

Zheng T, Santi MR, Bovolin P, Marlier LN, Grayson DR (1993) Developmental expression of the alpha 6 GABAA receptor subunit mRNA occurs only after cerebellar granule cell migration. Brain Res Dev Brain Res 75:91-103.

Zhu H, Luo L (2004) Diverse functions of N-cadherin in dendritic and axonal terminal arborization of olfactory projection neurons. Neuron 42:63-75. 